\title{
Exploring the Language of Death with Dignity: A Comparative and Critical Content Analysis of Canadian News Editorials
}

RYA KOBEWKA

Dr. Catherine Schryer

The Major Research Paper is submitted in partial fulfillment of the requirements for the degree of Master of Professional Communication

Ryerson University

Toronto, Ontario, Canada

August 14, 2013 


\section{AUTHOR'S DECLARATION FOR ELECTRONIC SUBMISSION OF A MAJOR RESEARCH PAPER}

I hereby declare that I am the sole author of this Major Research Paper and the accompanying Research Poster. This is a true copy of the MRP and the research poster, including any required final revisions, as accepted by my examiners.

I authorize Ryerson University to lend this major research paper and/or poster to other institutions or individuals for the purpose of scholarly research.

I further authorize Ryerson University to reproduce this MRP and/or poster by photocopying or by other means, in total or in part, at the request of other institutions or individuals for the purpose of scholarly research.

I understand that my MRP and/or my MRP research poster may be made electronically available to the public. 


\begin{abstract}
:
My major research paper (MRP) focuses on the language and arguments used in the debate surrounding medically assisted dying. This paper was interested specifically in how arguments are framed, and if arguments have changed regarding medically assisted dying in the past twenty years. My central research questions are: what are the arguments on both sides of the debate used in news editorials? And if the arguments changed - how did they change? To answer these questions I compared two case studies: (1) Sue Rodriguez and (2) Gloria Taylor. To compare the two cases I analyzed the editorial pages and online comments of major Canadian newspapers. I used key words in context (KWIC) to identify frames and arguments used. Six frames emerged: medically assisted dying legal (ML), medically assisted dying medical (MM), medically assisted dying moral (MMM), pro-life legal (PLL), pro-life medical (PLM), and prolife moral (PLM). The frames in support of medically assisted dying were used more than double the amount that pro-life frames were used; they were also used more frequently in 2012 than they had been in 1994. Further, there fewer overall KWICs used in 2012, but they were used correctly more often than in 1994. These findings suggest that the act of medically assisted dying is better understood and defined, and that it seems to have more support now than it did twenty years ago.
\end{abstract}




\section{Acknowledgments:}

I would like to thank Dr. Catherine Schryer for her excellent editing and suggestions, and for sharing her expanse of knowledge. I would also like to thank Dr. Joanne DiNova for her invaluable feedback.

Most importantly, I would like to acknowledge Sue Rodriguez and Gloria Taylor. Two brave

Canadian women whose memory will hopefully one day be honoured by a change to Canada's assisted suicide ban. 


\section{Table of Contents}

Author's Declaration ....................................................... 1

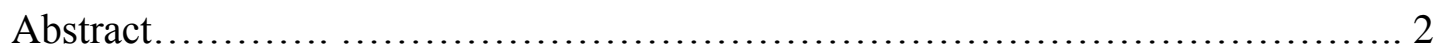

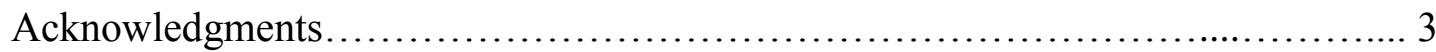

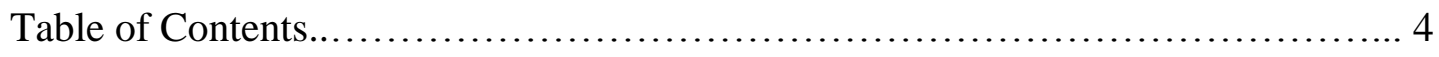

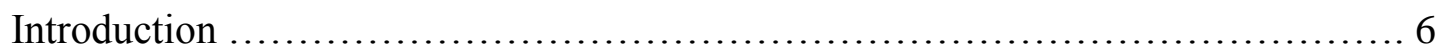

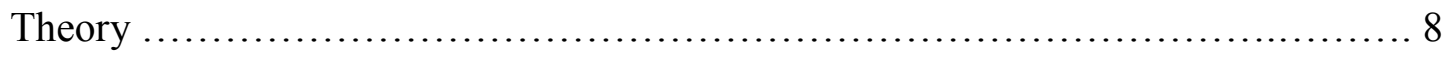

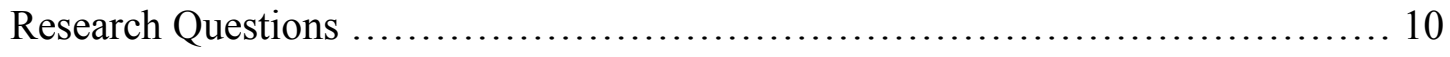

Literature Review ....................................................... 10

Death in the Media .................................................... 10

Frames and Language ................................................ 15

Editorials and the Power of Persuasion .................................... 21

Methodology: Document Collection ......................................... 27

Methodology: Methods of Analysis .................................................... 31

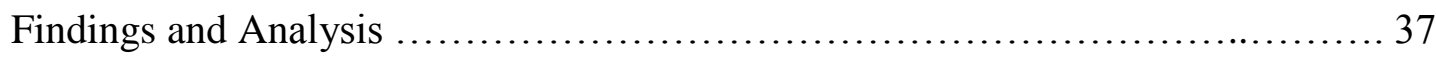

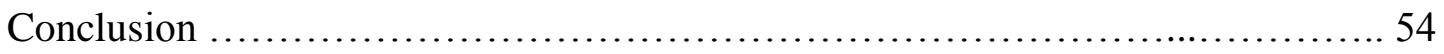

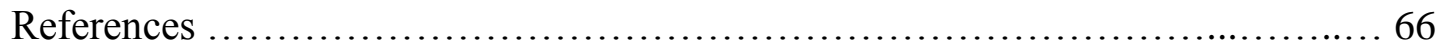

\section{List of Tables}

Table 1: Examples of Frames used in Analysis .................................. 37

Table 2: Key Words used in all Data ............................................. 38

Table 3: Key Words used in all Gloria Taylor Data ................................ 39

Table 4: Key Words used in all Sue Rodriguez Data ............................. 39

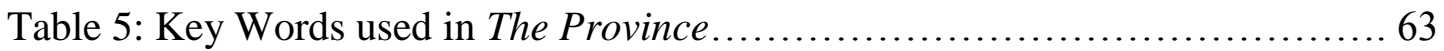

Table 6: Key Words used in The Vancouver Sun................................. 63

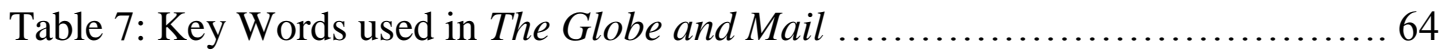


Table 8: Key Words used in The Toronto Star............................... 64

Table 9: Key Words used in The Toronto Sun...............................65

Table 10: Terms Referring to Sue Rodriguez in Newspaper Editorials ............ 43

Table 11: Key Words used incorrectly in all Sue Rodriguez Data ................ 44

Table 12: Key Words used incorrectly in all Gloria Taylor Data ................. 45

Table 13: Number of Frames Found in Documents .......................... 47

Table 14: Instances of Frames Occurring with Positive KWICs ................... 49

Table 15: Instances of Frames Occurring with Negative KWICs .................. 50

Table 16: Instances of Frames Occurring with Neutral KWICs ................... 51

Table 17: Number of Frames Found in Each Publication .......................... 53

\section{List of Appendices}

Appendix A: Newspaper Editorials Collected .............................. 59

Appendix B: Online Comments Collected ................................... 60

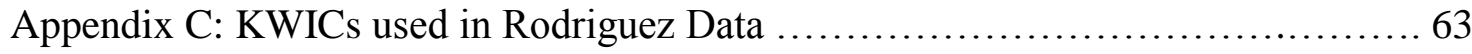




\section{Introduction}

Death is inevitable. How and when we die - is not as clear cut. The option to take death into our own hands is under constant criticism. Ending our own lives or receiving assistance for ending our lives faces continual debate. Debate is a necessary part of society. Reasoned, persuasive argument exists - especially when it involves controversial social issues. Marker and Smith (1996) explain "all social engineering is preceded by verbal engineering” (p. 83). One issue that faces continual debate is 'medically assisted dying', often called 'assisted suicide' or ‘physician assisted suicide'. For decades, two sides with multiple stakeholders have been going back and forth about this contested act. Atwood Gailey (2003) notes that "understanding the euthanasia controversy as a clash between institutions battling for power and individuals struggling for autonomy helps explain why the conflict has been joined by religious leaders and medical ethicists, along with physicians, attorneys, politicians, social justice activists, civil libertarians, and "moral entrepreneurs"' (p. 18). Along with the institutions fighting for and against 'medically assisted dying' are the media outlets covering the debate. The media have the potential to influence how the debate is defined and framed. Caplan and Turner (2004) clarify "how mainstream press outlets cover this convergence of the explicitly sensational and the explicitly ideological have contemporary political and social implications” (p. 39). Like other issues rooted in the sensational and ideological, there are implications for the media coverage of 'medically assisted dying.' Media coverage could potentially shape how people understand the topic and whether or not they support the practice. Thus, the potential implication for the press coverage of 'medically assisted dying' is legalization. For this reason, it seems important to understand how the media frame and argue for and against 'medically assisted dying'. 
This paper will examine how persuasive arguments are formed for or against 'medically assisted dying'. This paper will do so by analyzing the content of news editorials and online comments to try and understand which frames are used, and which terms are most frequently paired with which frames. Frames highlight and draw attention to particular parts of a story, even telling the story from a particular perspective. Van Gorp (2010) explains that "a core function of framing is to define issues" (p. 92). Kupyers (2010) continues, noting "frames highlight some features of reality while omitting others" (p. 300). Framing can exert a lot of influence especially if used on an unfamiliar topic, which 'medically assisted dying' is for many people. To carry out the analysis, I compared two case studies - the Sue Rodriguez and Gloria Taylor cases - to see if the arguments and frames changed regarding 'medically assisted dying' over a certain period of time in Canadian editorial coverage. Specifically, this paper compares news editorials and online comments that appeared during the Sue Rodriguez case and the Gloria Taylor case. These case studies have been chosen because of their similarities and differences; both cases occurred in the courts of British Columbia, and both of the plaintiffs were middle aged women suffering from ALS. However, the women had different outcomes - in the courtroom and in their eventual deaths. Rodriquez and Taylor fought for their right to die with dignity almost twenty years apart, Rodriquez in 1993/1994 and Taylor in 2011/2012. I have analyzed editorials and online comments from large Canadian news publications including The Toronto Star, The Toronto Sun, The Globe and Mail, The Vancouver Sun and The Province. By analyzing similar publications in similar time periods regarding the same topic, patterns emerged between the terms and frames used in editorials and online comments. 


\section{Theory}

The theoretical orientation of this paper is rhetorical. Rhetoric has deep ties with persuasion and the art of making arguments. Kuypers (2010) explains that "rhetoric involves the sharing of information and both active and passive attempts at persuasion" (p. 289). Forming persuasive arguments is at the heart of this topic. Language uses rhetorical devices to form such arguments. Ashipu (2013) states "[rhetoric] studies the effect of language and effect of persuasion" and "attempts to understand how linguistic devices create those effects" (p. 49). Understanding rhetoric is important because it can be found in all aspects of everyday life, and especially in healthcare. In fact, Dysart argues that medicine and rhetoric are completely interconnected with one another. She believes that medicine cannot exist without rhetoric. Dysart (2000) elaborates that "the practice of medicine requires deliberation, persuasion, consent and the determination of correct action in the absence of complete information, each a central concern of rhetoric. Rhetoric is thus an integral part of medicine" (p. 155). Just as rhetoric is important to medicine, it is also important to debates around 'medically assisted dying'. Through her research Dysart found that physicians with previous experience of 'voluntary suicide' were in favour of supporting 'medically assisting dying'. The doctors did not have approval in the eyes of the law, but through the persuasion of their patients - they felt swayed towards assistance.

In terms of rhetorical theory I will be specifically focusing on invention because it is the most applicable to written content. Invention, or the finding and developing of arguments, is what I believe is of most relevance to this MRP. Jasinski sees invention as a social process language is a social phenomenon and we should view invention accordingly (2001). Invention is always working to create arguments such as emotional appeals through language choice. 
Littlejohn and Foss (2008) comment that invention also affects context by noting, "invention refers to conceptualization - the process through which we assign meaning to symbols through interpretation, an acknowledgement that we do not simply discover what exists but create it through the interpretative categories we use" (p. 49). Invention seems to play a role in the creation of ideas and interpretation. The name itself even implies a certain act - ideas and arguments are not just there, but rather 'invented' in some way - molded and interpreted for use. Borchers (2006) takes it one step farther and states that invention is concerned with identifying issues, creating arguments that support the rhetor's position, and, most importantly, using proof to support this position. Invention is broken up into three areas: stasis, topoi and proof. Proof is at the root of persuasion. Borchers (2006) continues "persuasion must use demonstration, or proof" (p. 45). Persuasion uses ethos, logos and pathos to win an argument. As 'medically assisted dying' is such a sensitive, almost a taboo topic, related arguments often rely heavily on emotion, or pathos. Pathos is defined as appealing to the emotions or passions of a speaker or writer's audience. Appealing to emotion can be a powerful writing strategy. Humans are highly emotional beings and persuasive, emotionally-charged arguments can elicit response. Jasinski (2001) notes that "emotions produce different rhetorical effects that can function instrumentally as well as constitutively" (p. 428). Instrumental change occurs when agency, action or implementation is a result, and constitutive change means having the power to establish or institute a desired result. In this case both instrumental and constitutive change could both be very important to medically assisted dying. Rhetorical devices may be used to help reveal the arguments and frames applied in the newspaper editorials and online comments. 


\section{Research Questions}

This paper will focus on some of the similarities and differences in how news editorials covered the Sue Rodriguez case versus the Gloria Taylor case. If there are differences, do these differences indicate changing attitudes? To try and answer this concern I will be focusing on the following research questions:

- What are the arguments on both sides of the debate used in news editorials?

- If the arguments changed from the Rodriguez time period to the Taylor time period - how did they change?

This paper is also interested in identifying patterns between frames used and the publication they are found within. I will answer this issue by identifying arguments through key words in context and frameworks.

\section{Literature Review}

To better understand 'medically assisted dying' it is important to see its relation to the medical field, the law, and the media. My main areas of focus were to understand how death is covered in the media, how 'medically assisted dying' is covered in the media, how the media uses frames, how language and rhetorical devices appear, and how editorial pages are used as a tool. Three main themes emerged: death in the media, frames and language, and editorials and the power of persuasion.

\section{Death in the Media}

It is rare to open the newspaper these days and not be confronted by stories of death and disease. Human frailty and mortality link all of us together and the reality of death is reflected in 
news media. How we experience death is changing. Many people may now experience the death of a loved one as sterilized and possibly even impersonal due to medicalization. This medicalization is reflected in the coverage of death. Walter, Littlewood and Pickering (1995) describe the landscape of death in mainstream media as extremely medicalized. They believe death is in the domain of public officials and has become institutionalized. The changing face of death potentially affects not just the coverage of death, but death itself. The result of institutionalized death is that individuals have less power over their own demise (should they want the option). Atwood Gailey (2003) explains that "the atomization of death into discrete steps and technical procedures has thrown the definition of death itself into a philosophical quagmire" and that "reducing death to a series of technical steps obscures just when it is that death occurs" (p. 43). Walter et al. (1995) also argued that, although death is generally more institutionalized and private than it has been in the past, this absence of death is not reflected in the media, "there is one arena that makes death very public, and in which death makes a more than daily appearance: the mass media" (p. 581).

In fact, because most people now die in hospitals rather than homes, the news media does not just make death public but is one of the only ways many people actually encounter death. Atwood Gailey (2003) feels "the vast majority of American citizens in the twenty-first century encounter death primarily through the mass media "(p. 44). Clarke (2006) concurs "in the absence of personal experience with death today people rely on various media, among other things, for information, attitudes, beliefs and feelings about death and its meanings" (p. 286). However, some question if this mediated exposure to death is hurting us more than helping us in processing and understanding death. Understanding how death is covered in the media is important because it seems to be one of the primary ways the general public understand and 
process medically assisted dying. The lack of personal experience and exposure to death may make the public more easily manipulated in terms of their opinion on 'medically assisted dying.' Pollock and Yulis (2004) describe that "when audiences have relatively little alternative experience with an issue, the media are likely to exert substantial influence on public opinion" (p. 286). The media has the potential to exert influence over the public in matters of 'medically assisted dying' because news exposure may be a person's first experience with the issue.

The cases of Rodriguez and Taylor demonstrate the effect of media on the understanding of 'medically assisted dying'. For many, a celebrity's death is experienced before a family member's because of excessive news coverage. Woodthorpe (2010) explains that "in developed nations, where individuals can reach middle age without experiencing bereavement firsthand, witnessing the loss of a high-profile figure might be an individual's first encounter" (p. 154). Rodriguez and Taylor were ordinary women who became high-profile figures in Canada because of their courageous actions. For some, the coverage of Rodriguez and Taylor was perhaps their first exposure to ALS, degenerative disease and the desire for death. Coverage of ALS and 'medically assisted dying' is important because it does have real consequences in that it could affect whether or not it is legalized. Armstrong et al. (2006) concur, "disease [and death] garner attention in the public arena precisely because they have real consequences for individuals and for society as a whole" (pg. 736). This statement is not revelatory but it is important because it explains why death and disease are so prominent in news media, and it also offers some insight into the coverage of medically assisted dying.

Armstrong et al. (2006) believe that the type of disease that an individual dies from also has an effect on how much coverage that person receives post-mortem. Williamson et al. (2011) 
agree that "the media may affect how illness is perceived, in terms of its prevalence, severity and outcomes" (p. 547). The criteria of prevalence, severity and outcome dictate which illnesses make the news. These criteria could also be thought of as degree of the disease and its impact on quality and length of life. ALS, which led to the death of both Rodriguez and Taylor, meets these criteria. ALS or amyotrophic lateral sclerosis, or Lou Gehrig's disease, is a highly debilitating degenerative disease and the most common of the five motor neuron diseases. ALS causes muscle weakness and atrophy through the entire body due to the degeneration of neurons on the brain. The person affected loses control of their muscles and their body - losing the ability to speak, swallow and eventually breathe. It is not uncommon for people to choke or be suffocated to death. ALS acts relatively quickly and once diagnosed individuals have on average a little over three years before their inevitable death. However, from case-to-case this varies as to how much remaining time is quality, and how much is spent in the hospital hooked up with ventilators and feeding tubes. ALS certainly meets the criteria Armstrong references in terms of degree of severity and impact.

A dying person, fighting to die by their own means, adds another level of 'newsworthiness' to the story. Individuals who meet their end through 'medically assisted dying' are likely suffering to such a degree that their quality of life is greatly impacted. However, the criteria 'length of life' is perhaps pertinent for two reasons. First, fatal diseases can strike at any point in an adult lifespan. Adults facing a slow and painful death may consider 'medically assisted dying,' regardless of age. Second, a powerful argument used for 'medically assisted dying' is that many sick individuals have to cut their life short because they want to carry out their death while they are still physically able, since assistance is not legally available to them. This forces many people who still might have a few quality months, or even years, to cut their 
life short because of legal barriers to assistance. However, there is a fine line between those who want to end their live early because they are dying, and those who do not despite others impressions of their medical condition.

Haller and Ralph (2001) introduce the idea of recognizing and acknowledging a disability rights perspective. Their research takes a different stance- they discuss how the debate addresses those with disabilities. Their research focuses on the disability rights framework and how the death with dignity debate and subsequent news coverage can unknowingly promote 'ableism'. 'Ableism' is defined as a form of discrimination or prejudice against people with disabilities. Many individuals who are disabled want to be portrayed in the news as a minority group rather than an abnormal group. They worry that the generalization of language used in the media forces all people with disabilities into this debate even if they are not dying. Haller and Ralph (2001) explain that "this ideology that disabled people are 'worthless' can become a dominant cultural belief that imbeds news frames in 'physician assisted suicide' coverage" (p. 409). The disabled fear that they might either feel pressure to end their life, or are potentially killed because of assumptions about their living conditions and quality of life. Both the 'disability rights' framework and the ‘ableism' framework are important to consider when analyzing media. For example, a disabled person should not be referred to in any way as a victim. Wissner-Gross (1999) adds that "writers should not assume that people who have illnesses are in a constant state of suffering" (p. 182). Koch contributes more to this idea noting that physical and cognitive differences should not be a barrier to full personhood. In fact, there is a certain knowledge and richness living a life outside of the norm (2004). 


\section{Frames and Language}

Of importance is not just whose deaths are covered but how they are covered. How the media frames death can affect how we, as citizens and media consumers, feel about it. Joslyn and Haider-Markel (2002) state "considerable evidence supports the notion that opinions are shaped depending on how issues are framed" (p. 691). Miller (1997) agrees "research has begun to accumulate that shows a strong relationship between the ways that media present issues and the ways that the public perceives them" (p. 367). The potential impact upon audiences highlights the importance of frames. Frames are devices used to construct an image or perception in the telling or sharing of a news story. They centralize ideas to define issues for audiences. An example of how a frame was used can be seen in the coverage of $9 / 11$. In the days and weeks following 9/11, the media used a strong anti-Islamism and terrorism frame. The frame was used to put fear into the American people and paint the image of a 'bad guy' with whom America should go to war because of continuing terrorist threats. Kuypers (2009) states that "frames are so powerful because they induce us to filter our perceptions of the world in particular ways" (p. 181). Van Gorp and Vercruysse (2012) provide a simpler explanation, stating "frames are tools that are used in communication to decide which elements of reality should be selected" ( $p$. 1275). Atwood Gailey (2003) explains "news frames represent potent weapons in the symbolic struggle social movement activists wage over competing definitions and interpretations of social problems" (p. 4). News frames can be especially imperative in the case of disease and death. An example of a powerful frame can be seen in the editorial "Nurse Death Failed Us" (February 15, 1994, The Vancouver Sun). This editorial used a moral frame that was extremely critical of 'medically assisted dying'. The editorial made moral judgements, based on religion, calling Rodriguez a sad, desperate woman, comparing 'medically assisted dying' to abortion, and 
suggesting Svend Robinson was only involved because he was gay and would want to end his life after inevitably contracting HIV. The author also compared 'medically assisted dying' to practices in Nazi Germany. This editorial made strong moral judgements on every aspect of 'medically assisted dying', and the author framed his decisions as correct and moral using arguments based on societal good and the Bible.

Pollock and Yulis (2004) believe "media can play varied, influential roles in 'framing' critical public health issues of any kind" (p. 282). Clarke (2005) notes that "there is no doubt that the meaning of death is socially constructed" (p. 154). Like Walter et al., Clarke focused her research towards a specific type of media and how it communicated death - primarily on the effects of framing in relation to death in the news. She found three common frames that emphasized individual rights in the general coverage of death: (1) timing of death is a matter of personal control, (2) death is the new frontier of medicine, and (3) individuals should be able to make their own decisions. What these three frames have in common is the desire for death to be a matter of personal autonomy. However, despite a widespread wish for our eventual deaths to be in our own hands - this is not currently the case. From Clarke's findings we can see the emphasis of the role of medicine in death - which supports the notion by Walter et al. that the process of death has become highly routine and institutionalized. Death may be commonly framed as something we should have control over, but it is not always the reality because of the institutionalized manner of death in the twenty-first century. The role of medicine in framing the debate is further supported by Atwood Gailey who believes that all research will eventually reveal only two frames, medical and legal. 
As Armstrong et al. (2006) mentioned earlier, certain diseases make the news over others. When the mass media covers death, it is for one of two reasons: a public figure has died or a regular citizen has died in an unusual manner. The death with dignity debate fits into the second category, i.e., regular citizens choosing to die (sometimes publicly because of legal issues). Williamson et al. (2011) agree that "the reportage on health issues is not regulated by any medical representatives, but rather on what is deemed 'newsworthy' - issues that are rare, novel and dramatic rather than those of higher relative risk" (p. 549). ALS might not be newsworthy in itself, but coupled with the story of women fighting for their own death - that is rare, novel and dramatic.

Much of the previous literature about 'medically assisted dying' in the media is focused on the circumstances with which it makes the news. For example, Caplan and Turow (2004) focused their research on whether or not Dr. Keverokian's appearance on 60 Minutes affected mainstream news discussions. Pollock and Yulis (2004) studied news outlets across the United States to see if location changed how 'medically assisted dying' was framed. Some other research has focused on how often 'medically assisted dying' makes the news, and what are the different 'periods' of progress in the fight for 'medically assisted dying'. Marker and Smith (1996) analyzed the terminology and language changes occurring in the news over the past few decades as 'medically assisted dying' has progressed and evolved. The research carried out by Kalwinsky shares the most similarities with the research in this paper. Kalwisnky (1998) examined how frames were used in the New York Times between 1991 and 1996 in coverage of 'medically assisted dying.' Kalwinsky was interested in understanding how the strategies, functions and constraints of the news create meaning, and how that meaning is constructed into social reality. While there is some previous research about the framing of 'medically assisted 
dying;' there is general lack of information about how it is covered in different types of media specifically in editorials. This is a potential gap in the research to address.

Like the coverage of death in general, the coverage of 'medically assisted dying' uses a wide variety of frames. This variety is important because just as language sets context for the reader, so does the frame. Atwood Gailey (2003) sees the varied use of frames being especially true for the news coverage of 'medically assisted dying'. She explains that, "news narratives about 'euthanasia' bring into focus the cultural dimensions of the contest waged between individuals, medical institutions, and government agencies over control of the bodies of the aged, incompetent, severely disabled and dying" (p. 4). Atwood Gailey names three of the top stakeholders in this long standing debate as individuals, medicine and government. Dissimilarly, Mitchell (2007) believes it's less about stakeholders and more about arguments. He believes the arguments about 'medically assisted dying' can be filtered down into nine options:

- Cultural arguments that medically assisted dying is always wrong

- Religious arguments that suicide is morally wrong

- Utilitarian arguments against suicide

- The slippery slope argument

- Autonomy and moral claims to the right of medically assisted dying

- Medically assisted dying is not supported by the field of medicine

- Utilitarianism to morally justify medically assisted dying

- The lack of a constitutional right to medically assisted dying

- The legalization of medically assisted dying

Atwood Gailey synthesizes Mitchell's nine frames, believing that all of the key frameworks can be filtered into either medical or legal frames.

The pro-'medically assisted dying' medical frames would include the following claims:

- Medically assisted dying is the humane thing to do 
- Medicine already plays God.

The pro-life medical frameworks include the following claims:

- Death with dignity violates the Hippocratic Oath

- Alternatives exist

- Medically assisted dying causes worse suffering

- Medically assisted dying allows doctors to play God

The pro-'medically assisted dying' legal frameworks include the following claims:

- There is a right to die

- Current law is undermined by the practice happening anyways

- Potential exists to criminalize sympathetic families and doctors

The pro-life legal frameworks include the following claims:

- Euthanasia is a crime

- Legal safeguards are impossible - a slippery slope is inevitable.

I agree with Atwood Gailey that ultimately most frameworks are legal or medical. However, I feel she is missing a moral framework, encompassing religious, cultural and personal arguments.

Tucker and Steele (2007) are two scholars who focused less on frameworks and more on discourse, particularly the terminology surrounding the act itself. Their findings were similar to Clarke in that a focus on individual rights was important and should always connote the voluntary nature of the act. Further, Tucker and Steele (2007) also noted that beyond using terms related to individual choice, it is also important to use value-neutral terms. They believe 'suicide' should be left out altogether and that preferable terms including -- 'aid in dying'; 'patient directed dying'; 'physician assisted dying'; and 'physician assisted death' -- should be used when discussing end of life options. Tucker and Steele also emphasized the responsibility that some professionals have when discussing 'death with dignity'; doctors, lawyers, journalists, and 
medical care experts should recognize that they all have the opportunity to advance understanding through their choice of language. It certainly seems that the terms used to refer to the act of 'medically assisted dying' are just as important as the frames they are found within. Marker and Smith (1996) note that "in few social movements has the interpretation of words been as important as in the debate over 'euthanasia' and 'assisted suicide'. Additionally, in few social movements have words ever been so effectively used to blur, then completely obliterate, the line between the acceptable and the repugnant" (p. 82). The term chosen to represent the act of 'medically assisted dying' can have a large impact. Atwood Gailey (2006) emphasizes that "of all the ideational and symbolic forms used to represent reality, language is the most critical" ( $p$. 5). Van Dijk (1991) states "the implications of the use of the term are in that case closely tied to the attitudes about the people referred to" (p. 213). Some of the literature has mentioned Terri Schiavo and the media spectacle surrounding her case. In that situation where there was no shortage of media coverage, there was also no shortage of both objective and subjective language, with reporters using terms like 'prolonging her life', 'saving her life', 'murder', 'starvation' and 'right to die"' (Walker \& Black, 2009). The Schiavo case displayed the wide variety of language choices that are still used in supposedly 'neutral', unbiased news stories. Atwood Gailey (2003) notes language is never neutral. Even if language intends to be neutral or unbiased it is always steeped in layers of meaning.

The importance of language is supported by a study of Dutch newspapers and 'euthanasia' by Rietjens et al. (2013). They found that not only does language carry connotations but that terms are used interchangeably and incorrectly, and interchangeable terms can confuse the ethical debate. 'Assisted suicide' is ultimately carried out by the patient. This differs from 'euthanasia' where death is carried out by the physician, even if it is at the patient's request. As 
Michalsen and Reinhart (2006) define "euthanasia occurs when one person intentionally causes the death of another person, motivated by the desire to promote the best interest of the person who dies and using the most gentle means to achieve this end" (p. 1304). However, the usage is often implied much differently than the defined practice. Rietjens et al. (2013) explain "this has the potential to confuse the public debate about euthanasia, and means that physicians should be aware that their patients may have mistaken views about what euthanasia is, who it is for, and what circumstances lead to a decision to carry out euthanasia" (p. 7). Their study focused particularly on the term 'euthanasia'. They found that one quarter of news stories incorrectly used the term 'euthanasia' - most commonly mistaking it for 'medically assisted dying', or practices outside the scope of the law. 'Euthanasia' is not the only word used incorrectly in both hard and opinion news. Both types of reporting commonly make mistakes in their language choice. However, it is hard to know whether or not lexical mistakes are on purpose or a lack of understanding. Some scholars feel the term 'euthanasia' should be completely eradicated as the practice is rarely carried out. Michalsen and Reinhart (2006) state "when debating and publishing about end-of-life care, we should refrain from using this historically loaded term any longer" (p. 1309). This study reveals the importance and responsibility that journalists have in getting the language right. However - there is no guarantee in editorials or traditional news stories that the language will be correct.

\section{Editorials and the Power of Persuasion}

The results of the Dutch newspaper study are important because we are most often confronted with death through the news media, whether through traditional newspapers, online stories or television reports. The news works to accurately report the latest current events to its 
audience. The news determines which stories about death and disease are on the public's radar. Williamson et al. (2011) state "the media decide on which issues to present and the level of importance attached to them, influencing public understanding and awareness of disease" (p.547). Wissner-Gross (1999) adds "writers reveal bias as they subjectively choose the physical features upon which to focus" (p. 183). However, as seen in the study by Rietjens et al., the news does not always get the facts correct. Editorials are similar to the news in that they report current events. Ashipu (2013) explains "editorials are comments on news items of national concern which attract the attention of the editor" (p. 48). However, an editorial's approach to news items is much different than traditional news reporting as they can be much more explicit in their opinion. Rystrom (1983) comments "editorials are the anonymous opinion of the newspaper" (p. 10). There is also less accountability for editorials to get the language 'right'.

Editorials are an intriguing component of a newspaper. Editorials, opinion pieces and letters to the editor account for a small percentage of space but have the potential to make an impact. Stonecipher (1979) notes "the typical newspaper devotes about four percent of its nonadverting space to editorials comment" (p. 28). With such a small amount of dedicated space editorials have to work to make an impression. Fortunately for editorial writing - it is not limited like traditional reporting. It can be imbued with opinion, bias and emotion. Ashipu (2013) comments "an editorial may criticize, praise or merely discuss the actions of some public functionaries or groups" (p. 48). The main difference between editorials and the rest of the newspaper is that it is often used as a site of overt persuasion. Van Dijk (1991) explains "the editorial is the formulation place for newspaper ideologies" (p. 150). He continues "more than in news reports... the description of events in editorials is not restrained by criteria of assumed 'objectivity'. That is, the facts may be described in evaluative terms, thereby allowing the editor 
to express an opinion about the events" (p. 135). The editorial section is where a situation is defined or redefined by a news publication and where the ideology of the paper may be expressed. This can be done in a number of ways. Stonecipher (1979) claims "an editorial may be thought of as a journalistic essay which either attempts (1) to inform or explain, (2) to persuade or convince, or (3) to stimulate insight" (p. 40). Editorials may work on the offensive and even the defensive, defending their opinion, or opinions, in anticipation of possible criticism. Van Dijk (1991) observes, "editorials do not merely formulate opinions to be conveyed to the public, but also attack, defend, and give advice" (p. 134). However, in some cases editorials may not be persuading those with opposite opinions. They may only serve as a tool to reinforce and confirm prior knowledge and belief. Stonecipher (1979) sees "editorials written to persuade and influence may have greater success in reinforcing opinions and attitudes already held than in converting readers holding views initially opposed to those being advocated by the editorialist" (p. 45). Similarly, opinion pieces and letters to the editors which have been published have been selected for similar purposes. Letters to the editor both reflect the content of the newspaper and the interests of the readers. More importantly, they usually reflect the opinion of the newspapers. McCluskey and Hmielowski (2011) explain "[editorial letters] are typically reflecting the political stance of the paper" (p. 305). If the paper only has four percent of its space to establish its opinion, they are not going to waste it.

In the age of the internet, stating opinion has moved from the coveted four percent of printed news to a potentially unlimited amount of online comments and responses. Publishing news online changes the dynamic of who gets to be heard. Newspapers previously held the power over which comments and letters were published. Now, assuming a story is open for comments, anyone has access to this new platform of expression. Santana (2011) states 
"newspapers have been thrust into a Web 2.0 world, where, unlike the letter writers of a bygone era whose letters were vetted, anyone who has an opinion can be heard" (p. 67). This change has democratized the opinion function of the news, allowing for more citizens to have a say. McCluskey and Hmielowski (2011) explain that "audience letters do not necessarily represent public opinion ... online reader posts thus offer the potential for a range of opinions that more closely matches ideals of the public sphere" (p. 304). News organizations have less of a gatekeeping function in regards to online comments. However, they do still have the ability to delete any comments they deem inappropriate. Comments can be deemed inappropriate for a variety of reasons; sometimes, not including a real name is enough to see a comment removed. Similarly, letters to the editor are also edited for language and length. The main difference between letters to the editor and online comments is the sheer volume. A never-ending stream of online comments continue unless the comment board is closed by the news organization. Santana (2011) notes "online forums represent an entirely new opinion pipeline not seen in the letters-tothe-editor section of the printed newspaper" (pg. 77). In future research it would be of interest to compare letters to the editor and online comments remarking on the same news item.

The persuasive appeals of the editorial are of primary importance especially in terms of creating frames. The news media has influence over public opinion, particularly through its use of frames. Bonyadi (2010) adds "newspaper editorials have an important role in shaping public opinion" (p. 324). For that reason it should be understood how editorials persuade their readers. Strate et al. (2005) note "persuasion can be a source of power, especially when opinion is evenly divided" (p. 37). Three techniques that editorials have at their disposal to appeal persuasively are headlines, anecdotes and narratives. 
Headlines must not be overlooked as a tool of persuasion. Headlines are a guiding feature of editorials because they set the stage for the reader - particularly in terms of framing. Atwood Gailey (2003) says "headlines and subheads, which encapsulate a news story's main topic and theme, have been singled out as key structures in news framing" (p. 105). Van Dijk (1991) adds "[headlines] may bias the understanding process: they summarize what, according to the journalist, is the most important aspect, and such a summary necessarily implies an opinion or a specific perspective on events" (p. 51). An example of a persuasive headline was found in The Vancouver Sun; it reads “Assisted Suicide Opens a Pandora's Box on Death” (February 17, 1994). This headline suggests to readers that a 'medically assisted death' has happened and that the death is not for the good of society. Right from the beginning of the editorial, readers encounter a reference to 'Pandora's Box', a metaphor which is rarely viewed in a positive context. Overall, headlines play an important role in setting the tone for the reader.

Narratives and anecdotes are often understood to be the same literary device. In the case of this literature, they are defined and used differently. An anecdote is a retelling of a (usually) brief story that actually happened. A narrative is a lengthier story that may or may not be true and that has a moral. Similarly, anecdotes also function to convince the reader. An anecdote is a short account of an incident or an event often from a personal perspective. Atwood Gailey (2003) notices, "by imbuing news stories with dramatic and narrative meaning, anecdotes also represent causes and solutions more persuasively than other rhetorical elements" (p. 106). Anecdotes help make editorials real and bring the issues discussed to life. An example of a powerful anecdote can be seen in a document collected from The Vancouver Sun (February 15, 1994). The editorial was written by Svend Robinson and told his personal experience of witnessing Rodriguez's death. He walks through the day's events, vividly describing how he held her in her arms as she 
passed away. This anecdote makes her death tangible, and as a reader it is hard not to get caught up in her final moments as described by Robinson. Anecdotes make stories real and relatable for those who weren't there to witness the experience firsthand.

The third persuasive appeal is narrative - which can be divided into explanation and moral. Chang (2009) elaborates "a narrative involves 'one or more episodes consisting of actors engaged in actions to achieve goals' and contains a 'sequence initiated by some events and actions result[ing] in outcomes"' (p. 21). Through the eyes of the author we read their personal narrative of what happened and why it happened. But most importantly, we read the moral conclusions. Van Dijk (1991) sees the moral narrative as "a category of prediction or recommendation, which we subsume under the broader category of moral, and which focuses on the future: what will happen? or what should or should not be done?” (p. 133). In the case of narratives about 'medically assisted dying', - the author might explicitly state his or her opinion as to what the future of 'medically assisted dying' should look like. An example can be seen in a document collected from The Province (February 15, 1994). The writer firmly denounces 'medically assisted dying' and describes a bleak future of victimization, state killing, abortion and elder abuse. He persuasively predicts a landscape of unwanted death. Chang (2009) sees narratives as extremely persuasive, "narrative editorial content may cognitively and affectively involve readers more than facts-based editorial content" (p. 23). Ultimately, a narrative provides writers with an opportunity to overtly state their opinion on the issue. Persuasive appeals are helpful for a content analysis in that they help the researcher more easily identify the frames being used. As much as persuasive appeals seamlessly 'code' in content, they also work to 'decode' content and determine how it is being used to sway readers. 
Each of these persuasive techniques - headlines, narratives and anecdotes - is most effective when covering a topic in a timely manner. Stonecipher (1979) explains "the persuasion message should be as timely as possible, particularly when it deals with controversial topics or interesting subject matter" (p. 174). These three persuasive devices help further draw the connection between the study of newspaper editorials and rhetorical theory. Ashipu (2013) comments "[rhetoric] emphasizes essentially the linguistic devices, the social aspect of language and its impact in a particular context" (p. 49). The editorial is primarily a piece of persuasive writing, so it unsurprising that it employs numerous persuasive and rhetorical techniques to accomplish its goal.

\section{Methodology}

\section{a) Document Collection}

My research method involves the content analysis of news editorials. The documents I chose had the advantage of being both rich in information and available to analyze. This seems to be a common reason why newspapers are used for document collection. Pollock and Yulis (2004) used newspapers in their research for two reasons; they are readily available and they provide an analysis beyond text in terms of photos and visuals. The availability of editorials varied depending on what was written on each case, but all of the newspapers used for this research were available in public libraries, both on microfilm and online. Truth value is one of the major advantages of document analysis, although the truth value depends on one's own personal reading of each editorial. As explained by Lindloff and Taylor (2011) "the evaluation of a document's truthfulness depends on your analytic goal in using it" (p. 239). Truth value is defined as being the extent to which documents can be used as a reliable source. Editorials and opinion pieces have seemingly little in common with a document that could fall under the 
'reliable source' category. However, Lindlof and Taylor (2011) note that truth is a variable standard and documents of a personal nature can be assessed for truth value. They state, "we [the researchers] are mostly interested in how the content reflects the author perspective... [and we believe] the document can be safely regarded as accurately representing the author's view of reality" (p. 238). The truth of the documents lies in the authors 'truth' and what they believe to be true. In this paper, the documents are reliable because they reflect opinion which is the objective of the analysis of this paper. Lindlof and Taylor further mention that one of the greatest strengths of document analysis is that documents can create links between the past and the present, exactly what this paper is intending to do. Linking the past and present through document analysis is only strengthened when comparing two similar events. Hansen et al. (1998) explain that "a helpful strategy for profiling and understanding the media coverage of a specific event may also include the sampling and analysis of coverage of a comparable event" (p. 102). Rodriguez and Taylor lived through and fought for the exact same thing twenty years apart there is no shortage of comparable circumstances in the events at the end of their lives.

Maximum variation sampling was used for data collection. This sampling strategy was used in order to cover the widest array of potential opinions. Maximum variation sampling helps reveal how an idea is understood by different people, in different settings, at different times. To accomplish this, I used a wide variety of Toronto, Vancouver and national newspapers. I collected documents relating to Rodriguez from three Toronto based newspapers, The Globe and Mail, The Toronto Sun, and The Toronto Star, and two Vancouver based newspapers, The Province and The Sun. I collected documents relating to Taylor from The Toronto Sun, The Globe and Mail, The National Post and CBC. There were no B.C. news outlets included in the Taylor results because none of the Vancouver papers allowed for online comments of their 
Taylor stories. These news outlets helped provide me with a wide range of perspectives from left to right on the political spectrum. The political leaning of each paper was determined by their ownership and historical preferences. To find such editorials, I used strict search parameters in terms of timelines. The final decision on what was to be collected came down to availability rather than preference. Documents collected for Sue Rodriguez date between February 13, 1994, and February 21, 1994. Rodriguez ended her life on February 12, 1994, and the following week garnered much media attention. From the newspapers relating to Rodriguez, I collected (as much as was available) editorials by regular contributors, guest writers or letters to the editor which had an opinion on medically-assisted dying, and commented directly on the Rodriguez case. To collect these editorials I searched the microfilm for each newspaper to ensure no editorials, opinions pieces or letters had been left out.

The methods varied slightly for the collection of data related to Gloria Taylor. Documents collected for Taylor were originally going to be for the time period of August 11, 2012, through until August 20, 2012. Taylor received her final court verdict on August 10, 2012 - the verdict that permitted her to seek a doctor's assistance in the ending of her life. This original date was chosen because it was more 'newsworthy' than her eventual death, and was the first difference between the cases of Taylor and Rodriguez. However, there were almost no editorials or letters to the editors in the week following the court's decision. For this reason, the dates for Taylor's data collection were switched to the week of her death on October 5, 2012. Again, there were no editorials or letters responding to the initial news coverage of her death. But in the past twenty years media has greatly evolved which allowed for new opportunities - in the form of online comments and responses. McCluskey and Hmielowski (2011) elaborate, "the nature of the technology allows for nearly instantaneous opinion expression and response" (p. 
316). All the online comments and responses were collected from stories posted on October 5 , 2012, the day of Taylor's death. The criteria for comments and responses to be collected were that they must use a term for 'medically assisted dying'. Comments were omitted that did not explicitly refer to 'medically assisted dying' or Gloria Taylor. For example, in the online responses there were multiple items that mentioned either supporting or opposing 'medically assisted dying' but did not name the term or act. These were excluded. Collecting comments through this method was more time intensive as each posted comment for every online story needed to be read. This method also created a discrepancy in how many responses were collected from each outlet due to appropriateness. Despite the extra work and inconsistency in numbers from each outlet, this collection process provided more relevant data to answering the research question because all inclusions met the criteria.

Based on the criteria outlined in methodology there were a total of 44 documents to analyze (see Appendix A and B). The total number of documents was broken down into 23 documents collected related to Rodriguez and 21 documents related to Taylor. The 23 documents collected from February 1994, were from five major newspapers, which included: six documents collected from The Vancouver Province, seven from The Vancouver Sun, five from The Globe and Mail, three from The Toronto Star, and three from The Toronto Sun. The sharp difference in editorials collected from Vancouver versus Toronto newspapers is unsurprising considering that Rodriguez was based in British Columbia. Stonecipher (1979) notes that editorial choices are highly dependent upon geography; the home province of each of the papers could explain the discrepancy in numbers of the collected data from 1994. The 21 documents collected from October 5, 2012, included: three online comments and responses collected from The National Post, three from The Globe and Mail, nine from $C B C$ and six from The Toronto Sun. Overall, the 
length and scope of data collected ranges from short one sentence online responses to full one page opinion pieces.

\section{b) Method of Analysis}

This paper used content analysis because it focuses on understanding context and language. When it comes to content analysis, context is just as important as content. Dey (2001) explains that information is context when "a piece of information can be used to characterise the situation of a participant in an interaction" (p. 5). Content analysis casts a wide net when collecting information for analysis because it is searching to find embedded meanings. Those meanings can be uncovered by looking at the context of the content. Hansen et al. (1998), state "the aim of content analysis in media research has more often been that of examining how news, drama, advertising and entertainment output reflect social and cultural issues, values and phenomena" (p. 92). Content analysis is used best when entire blocks of text can be analyzed. Because editorials are typically brief, content analysis was possible for me to accomplish, even with the high number of editorials collected from 1994. This method helped me answer the research question because I was able to identify the keywords in context and arguments being used. Being able to identify both the context and arguments used allowed me to see how editorial content shifted over time. To analyze the data I borrowed from the methodology developed by Clarke (2005) in her study of magazine content. Her initial pass of each article was to find the manifest and latent content, searching out what was explicitly stated and what was left out. Her second read of each article was focused on the language, frames and discourse that were explicitly related to death. This paper applies this process to newspaper editorials, opinion pieces, letters to the editors and online responses and comments. 
To carry out my content analysis, I used keyword in context (KWIC). Weber (1985) believes that keyword in context draws attention to the variation in word meaning and usage. Keywords are only key in the context of which they appear or are studied. Scott and Tribble explain (2006) "a key word is an ordinary word which happens to be key in a particular text" ( $p$. 78). For example, 'suicide' and 'euthanasia' are two regular words, but in the context of this research they take on very different meanings and are examples of KWICs. I decided upon KWIC for two primary reasons. First, 'medically assisted dying' is an issue steeped in euphemisms that can be used as keywords. There are a plethora of terms used including 'assisted suicide', 'euthanasia', 'murder', 'physician assisted suicide', 'aid in dying', 'assisted dying', etc. Second, some of these terms are used on both sides of the debate but in much different contexts. Krippendorff (2004) states "a key word in context list enables content analysts to examine different uses of the same word" ( $\mathrm{p}, 266)$. KWIC helps draw attention to the variation or consistency in word meaning. Weber (1985) adds "KWIC lists show the context in which each word appears" (p. 44). Krippendorff (2004) notes "research is re-search, a repeated search for patterns" (p. 125) KWIC generally help identify patterns such as frames in similar documents. Authors use frames to construct subjective and specific ways that their readers may understand and interpret a narrative. Kuypers (2010) elaborates that "frames can be detected by looking for specific properties within news narratives: key words, metaphors, concepts, symbols, visuals images, and names given to persons, ideas, and actions (p. 301). Van Gorp (2010) also includes historical examples, catchphrases, depictions, actors, actions and settings, lexical choice, groups and appeals (emotional, logical and ethical) to the list of identifiable framing devices. This wide array of framing devices were considered when analyzing documents to determine frames used. To identify how the keywords were used and which patterns emerged, I coded and categorized 
my documents for frames and/or arguments. I looked to see which arguments for/against 'medically assisted dying' were used with which terms.

To determine the context of each of the KWICs I followed a number of steps for all of the documents collected. The first step was to determine the tone of each document. Using Clarke's definitions, each document was initially read for both manifest and latent content to determine the overall tone. Clarke (2006) defines manifest as content that is explicitly stated - the intended and surface content - and latent content as less obvious, underlying themes. Van Djik (1991) uses an excellent metaphor for manifest and latent content, "the text is like an iceberg of information of which only the tip is actually expressed in words and sentences. The rest is assumed to be supplied by the knowledge scripts and models of the media users, and therefore usually left unsaid" (p. 181). Once manifest and latent content were used to determine the tone, each of the documents was then determined to be favourable, unfavourable or balanced/neutral. Favourable is defined as a document being mostly, or completely, in favour of 'medically assisted dying.' Balanced/neutral is defined as reserving judgement about 'medically assisted dying.' Unfavourable is defined as a document that is mostly, or completely, against 'medically assisted dying.' Each document was determined to be favourable, unfavourable or balanced/neutral based on the overall content of the article, the terms used and the quotes included. An example of a favourable document is an editorial from The Vancouver Sun entitled “Criminal Charges Would Insult Sue Rodriguez" (February, 15, 1994). The editorial defends Rodriguez and the doctor who assisted her while urging the court to revisit the law. An example of an unfavourable document is an editorial from The Province (February 15, 1994). The editorial entitled "Making a Hero of Rodriguez for Giving Up" discusses how Rodriguez has unfairly been labelled a hero when instead she is just an ill woman whom we should feel sorry 
for. The author compares Rodriguez to a real hero in his opinion - a man also dying from ALS who wrote a book instead of asking to change the law. An example of a balanced/neutral document is an editorial entitled "Let's Talk" (February 17, 1994, The Toronto Sun). The editorial addresses the possible agenda of Svend Robinson in assisting Rodriguez. It neither vilifies nor commends Robinson's actions. Rather, it discusses why he may have done what he did and asks readers not to judge because we do not know his true motivations.

The second step of the process was to identify all of the terms and/or euphemisms referring to 'medically assisted dying' of the actual death of either woman. The terms for each woman's actual death were included because they varied greatly and this was where some of the most interesting euphemisms appeared. Each term was then coded as positive, neutral or negative. Each usage of the term was then assigned to a category based on the overall tone of the particular document, paragraph, and sentence. Not infrequently, positive terms were found in negative documents and vice versa. An example of these coded terms can be seen with the KWIC 'suicide'. In a positive context' suicide' was used as 'someone helped her commit suicide". The use of the word' helps' implies that 'suicide' was an appropriate action. In a negative context it was used as "have access to adequate hospice and palliative care so that fewer of them feel drawn to suicide". This quote both endorses palliative care as an alternative and posits 'suicide' as something we should be encouraging others not to participate in. Even using the word 'them' implies an othering, and a choice between right and wrong. In a neutral context it was used as "the death of Sue Rodriguez demonstrates the need for a new suicide law". The editorial might feel that legislation is needed but the editorial context overall was negative despite this statement. Further the author stated a new 'suicide' law rather than a new 'assisted 
suicide' law. The use of 'suicide' over 'assisted suicide' is a word choice that seems to strongly indicate how the author feels about the act.

Some of the KWICs were used interchangeably, and as a result were used incorrectly. I noted which KWICs were used incorrectly most frequently, and whether those KWICS were used incorrectly in a positive, negative or neutral context. The two terms that were included in this count were 'euthanasia' and 'legalized euthanasia' - both of which were frequently used incorrectly. I believe they are so commonly misused because of their ambiguity. Writers have the opportunity to take advantage of their audience knowing that the term is generally misunderstood. Michalsen and Reinhart (2006) also found this term frequently misused, noting that "the term euthanasia has been used inappropriately in this context" (p. 1304). An example of 'euthanasia' used incorrectly in a positive way is a "battle for change in the laws that govern euthanasia was a heroic one". The use of the term 'euthanasia' is incorrect as that is not what Rodriguez was fighting for, but the writers used the word in context of fighting a battleimplying she was fighting a good fight. An example of 'legalized euthanasia' used incorrectly in a negative way is "many of the old and infirm who would surely be victimized by legalized euthanasia" (February, 15, 1994, The Province). The word victimized implies that 'legalized euthanasia' is a harmful practice, even though the term is being used mistakenly by the author. An example of 'legalized euthanasia' used in a neutral way is "Rodriguez, who was 43 , became a cause célèbre when she took her fight for legalized euthanasia to the courts" (February, 15, 1994, The Province). While the document states that she is fighting in the courts, the author neither states if this is a bad or good thing and the author purposely uses 'legalized euthanasia' - an incorrect term - whereas they have used 'assisted suicide' correctly elsewhere in the editorial. Atwood Gailey (2003) adds that this is a common occurrence: "both pro-life activists and RTD 
[right to die] supporters tend to define euthanasia broadly - although for dramatically different reasons" (p. 135). Analyzing when 'euthanasia' and 'legalized euthanasia' are used incorrectly is not central to the research question, but it adds an interesting dimension to understanding how these keywords are used.

The third step of the process was to determine which of the frameworks had been utilized in the document - keeping record of which terms were most commonly paired with which frameworks. I followed the method in the newspaper study conducted by Pollock and Yulis (2004). In their research they analyzed a number of newspapers from across the United States to determine if location was a factor in how 'medically assisted dying' was framed in local news. To conduct their research Pollock and Yulis considered each news article as an individual sampling unit, which was then coded as favourable, unfavourable or balanced/neutral. They then looked to see which frameworks for or against 'medically assisted dying' were most commonly found with favourable, unfavourable and balanced/neutral news coverage. To apply this method to my own research meant coding the documents, or sampling units, as favourable, unfavourable or balanced/neutral and then analyzing which frameworks were most commonly used with each. Six frameworks emerged: medically assisted dying legal (ML), medically assisted dying medical (MM), medically assisted dying moral (MMM), pro-life legal (PLL), pro-life medical (PLM), and pro-life moral (PLM). These frameworks can be below seen in Table 1. Each of these frameworks encompasses multiple arguments as outlined previously in the literature review. However, for ease of coding and analysis, broad frameworks were considered most effective for this paper. 
Table 1. Examples of Frames used in Analysis

\begin{tabular}{|l|l|l|}
\hline \multicolumn{1}{|c|}{ Frame } & \multicolumn{1}{|c|}{ Definition } & \multicolumn{1}{c|}{ Example } \\
\hline $\begin{array}{l}\text { Medically assisted } \\
\text { dying legal (ML) }\end{array}$ & $\begin{array}{l}\text { Framing the argument in favour of } \\
\text { medically assisted dying by making } \\
\text { legal claims. }\end{array}$ & $\begin{array}{l}\text { The government wrongly refused } \\
\text { to grant Rodriguez her request } \\
\text { (February 15, 1994, The } \\
\text { Vancouver Sun) }\end{array}$ \\
\hline $\begin{array}{l}\text { Medically assisted } \\
\text { dying medical (MM) }\end{array}$ & $\begin{array}{l}\text { Framing the argument in favour of } \\
\text { medically assisted dying by making } \\
\text { medical claims. }\end{array}$ & $\begin{array}{l}\text { Health care workers are currently } \\
\text { burdened because aid in dying is } \\
\text { happening anyways (February 21, } \\
\text { 1994, The Globe and Mail) }\end{array}$ \\
\hline $\begin{array}{l}\text { Medically assisted } \\
\text { dying moral (MMM) }\end{array}$ & $\begin{array}{l}\text { Framing the argument in favour of } \\
\text { medically assisted dying by making } \\
\text { moral or cultural claims. }\end{array}$ & $\begin{array}{l}\text { Right to personal determination } \\
\text { and choice over one's body } \\
\text { (October 5, 2012, CBC Online) }\end{array}$ \\
\hline Pro-life legal (PLL) & $\begin{array}{l}\text { Framing the argument in favour of } \\
\text { pro-life by making legal claims. }\end{array}$ & $\begin{array}{l}\text { Doctors will be able to kill } \\
\text { without prosecution (February 15, } \\
\text { 1994, The Province) }\end{array}$ \\
\hline $\begin{array}{l}\text { Pro-life medical } \\
\text { (PLM) }\end{array}$ & $\begin{array}{l}\text { Framing the argument in favour of } \\
\text { pro-life by making medical claims. }\end{array}$ & $\begin{array}{l}\text { Legalized aid in dying will lead to } \\
\text { victimization (October 5, 2012, } \\
\text { CBC Online) }\end{array}$ \\
\hline $\begin{array}{l}\text { Pro-life Moral } \\
\text { (PLMM) }\end{array}$ & $\begin{array}{l}\text { Framing the argument in favour of } \\
\text { pro-life by making moral or cultural } \\
\text { claims. }\end{array}$ & $\begin{array}{l}\text { Rodriguez was a sad woman who } \\
\text { had no courage and wanted an } \\
\text { easy way out (February 15, 1994, } \\
\text { The Vancouver Sun) }\end{array}$ \\
\hline
\end{tabular}

To determine the frame of each document, I will search for framing devices based on the criteria previously outlined.

\section{Findings and Analysis}

The analysis uncovered a number of different KWICs for both the Rodriguez data and the Taylor data. In total there were 17 KWIC, as seen in Table 2. Of the 170 instances in which KWICs were used, $43 \%$ were identified as positive, $39.5 \%$ as negative and $17.5 \%$ as neutral. The KWICs with the highest individual counts were 'assisted suicide,' 'die with dignity' and 'physician assisted suicide.' Of the 17 KWICs identified, these three KWICs accounted for $59.5 \%$ of overall KWIC use. The wide variety of word choice should not be viewed as inconsequential. Van Dijk (1991) notes "lexicalization of semantic content is never neutral: the 
choice of one word rather than another to express more or less the same meaning, or to denote the same referent, may signal the opinions, emotions, or social position of a speaker" (p. 53). In this case, the speaker is the editorialist or opinion writer.

Table 2. Key Words used in all Data

\begin{tabular}{|l|c|c|c|c|}
\hline Term for the Act & Positive & Negative & Neutral & Overall \\
\hline Active Euthanasia & 1 & & & $\mathbf{1}$ \\
\hline Assisted Suicide/Legally Assisted Suicide & 25 & 19 & 10 & $\mathbf{5 4}$ \\
\hline Criminal Act & & 1 & & $\mathbf{1}$ \\
\hline Death & 2 & & & $\mathbf{2}$ \\
\hline Die with Dignity/Right to Die & 13 & 2 & & $\mathbf{1 5}$ \\
\hline Euthanasia & 8 & 8 & 8 & $\mathbf{2 4}$ \\
\hline Good Death/Compassionate Death & 4 & & & $\mathbf{4}$ \\
\hline Inhumane Death & & 1 & & $\mathbf{1}$ \\
\hline Kill/Killed & & 11 & & $\mathbf{1 1}$ \\
\hline Legalized Euthanasia & & 3 & 1 & $\mathbf{4}$ \\
\hline Manslaughter/Murder & & 4 & & $\mathbf{4}$ \\
\hline Mercy-Killing/Terminating the Patient & & 7 & 3 & $\mathbf{1 0}$ \\
\hline $\begin{array}{l}\text { Physician Assisted Suicide/Doctor assisted } \\
\text { suicide }\end{array}$ & 15 & 3 & 5 & $\mathbf{2 3}$ \\
\hline Premature Death & & 1 & & $\mathbf{1}$ \\
\hline State Killing & & 3 & & $\mathbf{3}$ \\
\hline Suicide & 5 & 3 & 3 & $\mathbf{1 1}$ \\
\hline Voluntary Euthanasia & $\mathbf{7 3}$ & $\mathbf{6 7}$ & $\mathbf{3 0}$ & $\mathbf{1 7 0}$ \\
\hline & $\mathbf{( 4 3 \% )}$ & $\mathbf{( 3 9 . 5 \% )}$ & $\mathbf{( 1 7 . 5 \% )}$ & $\mathbf{( 1 0 0 \% )}$ \\
\hline
\end{tabular}

There is much at stake when deciding upon word choice. Marker and Smith (1996) further elaborate "the success or failure of political or social revolutions often depends on the terms used in the debate" (p. 106). Indeed, it is promising to see that 'physician assisted suicide'/'doctor assisted suicide' and 'assisted suicide'/'legally assisted suicide' account for $45 \%$ of all KWICs. These two KWICs are the most accurate of all KWICs observed, and preferred by many proponents of the movement. The variation of data was reflected in not only percentages, but by word choice. The variation in word choice can be seen in Table 3 and Table 4. 
Table 3. Key Words used in all Gloria Taylor Data (October 5-6, 2012)

\begin{tabular}{|l|l|l|l|l|}
\hline Term for the Act & Positive & Negative & Neutral & Overall \\
\hline Assisted suicide & 7 & 4 & & $\mathbf{1 1}$ \\
\hline Die with Dignity/Right to Die & 9 & & & $\mathbf{9}$ \\
\hline Euthanasia & 2 & & $\mathbf{2}$ \\
\hline Inhumane death & & 1 & & $\mathbf{1}$ \\
\hline Killing & & 2 & & $\mathbf{2}$ \\
\hline $\begin{array}{l}\text { Physician assisted suicide/medically assisted } \\
\text { suicide }\end{array}$ & 3 & & & $\mathbf{3}$ \\
\hline Suicide & & 1 & & $\mathbf{1}$ \\
\hline \multicolumn{1}{|c|}{ TOTAL } & $\begin{array}{c}\mathbf{2 1} \\
\mathbf{( 7 2 . 5 )}\end{array}$ & $\begin{array}{c}\mathbf{8} \\
\mathbf{( 2 7 . 5 \% )}\end{array}$ & & $\begin{array}{c}\mathbf{2 9} \\
(\mathbf{1 0 0 \%})\end{array}$ \\
\hline
\end{tabular}

Table 4. Key Words used in all Sue Rodriguez Data (February 12-21, 1994)

\begin{tabular}{|c|c|c|c|c|}
\hline Term for the Act & Positive & Negative & Neutral & Overall \\
\hline Active Euthanasia & 1 & & & 1 \\
\hline Assisted Suicide/Legally Assisted Suicide & 18 & 15 & 10 & 43 \\
\hline Criminal Act & & 1 & & 1 \\
\hline Death & 2 & & & 2 \\
\hline Die with Dignity/Right to Die & 4 & 2 & & 6 \\
\hline Euthanasia & 6 & 8 & 8 & 22 \\
\hline Good Death/Compassionate Death & 4 & & & 4 \\
\hline Kill/Killed & & 9 & & 9 \\
\hline Legalized Euthanasia & & 3 & 1 & 4 \\
\hline Manslaughter/Murder & & 4 & & 4 \\
\hline Mercy-Killing/Terminating the Patient & & 7 & 3 & 10 \\
\hline $\begin{array}{l}\text { Physician Assisted Suicide/Doctor assisted } \\
\text { suicide }\end{array}$ & 12 & 3 & 5 & 20 \\
\hline Premature Death & & 1 & & $\mathbf{1}$ \\
\hline State Killing & & 3 & & 3 \\
\hline Suicide & 5 & 2 & 3 & 10 \\
\hline Voluntary Euthanasia & & 1 & & 1 \\
\hline TOTAL & $\begin{array}{c}\mathbf{5 2} \\
(\mathbf{3 7 \%})\end{array}$ & $\begin{array}{c}59 \\
(42 \%)\end{array}$ & $\begin{array}{c}30 \\
(21 \%)\end{array}$ & $\begin{array}{c}141 \\
(100 \%)\end{array}$ \\
\hline
\end{tabular}

The KWICs, as indicated in Table 4, included the following:

- active euthanasia

- assisted suicide

- criminal act

- death 
- die with dignity

- euthanasia

- good death

- inhumane death

- killed

- legalized euthanasia

- murder

- mercy-killing

- physician assisted suicide

- premature death

- state killing

- suicide

- voluntary euthanasia

In some cases terms were paired together because they conveyed a similar meaning. They could not stand alone as individual KWICs with independent meanings. It was decided that these terms were too similar to identify as individual KWIC. These pairs were:

- assisted suicide and legally assisted suicide

- die with dignity and right to die

- good death and compassionate death

- kill and killed

- murder and manslaughter

- mercy killing and terminating the patient

- physician assisted suicide and doctor assisted suicide.

Some KWICs appeared to imply similar meaning but were kept separate for specific reasons. For instance, 'active euthanasia', 'euthanasia', 'legalized euthanasia' and 'voluntary euthanasia' were all designated as separate KWICs. These decisions were made because each term was used to imply different types of 'euthanasia', each connoting their own meaning. For example, 'active euthanasia' refers to when a person deliberately intervenes and acts to end a person's life, whether or not by request. This is different than 'voluntary euthanasia' in which a person makes a conscious decision to die and asks for help. 
In total, for the Rodriguez data set, there were 141 KWICs used across 44 pieces of data. There were 52 KWICs used in a positive context, 59 KWICs used in a negative context and 30 KWICs used in a neutral context. In total, for Taylor, there were 29 KWICs used across 21 pieces of data. There were $21 \mathrm{KWICs}$ used in a positive context, $8 \mathrm{KWIC}$ used in a negative context and 0 KWICs used in a neutral context. Only 37\% of Rodriguez's KWICs were positive, in contrast with $72 \%$ of Taylor's KWICs. This finding implies that over the past twenty years 'medically assisted dying' is gradually being referred to through more positive terms. This change could be in part due to changing attitudes in Canada. However, it should be noted that this result may be skewed because of the methods of document collection. Online responses were omitted that did not directly name a term; it is unknown whether the remaining online comments were against or in favour of 'medically assisted dying'. But from the data collected, it seems as though terms in favour of 'medically assisted dying' are on the rise. This finding suggests changing favourable attitudes towards 'medically assisted dying'. One factor that has changed from the early 1990's is the rise in the number of senior citizens in Canada. Canada's baby boomers are the largest portion of the population. Possibly more and more seniors are considering their end of life options as they age. Interestingly, these results are unexpected with an aging population. Pollock and Yulis (2004) found "the greater the proportion of older citizens, the less favourable the coverage of physician assisted suicide." (p. 287). This is a potential area for further research - understanding whether age factors into opinion and term choices for 'medically assisted dying'.

The data collected for Taylor revealed that no single publication had an overwhelmingly negative or positive KWIC count. This was different from the Rodriguez data in which the numbers of KWICs were mostly positive or mostly negative depending on the publication. The 
discrepancy in these results may be due to the fact that double the amount of documents were collected for Rodriguez. The varying KWIC perspectives in the Rodriguez data can be seen in Tables 5, 6, 7, 8 and 9 (see Appendix C). From these five tables it becomes clear which newspapers included KWIC in a positive, neutral, or negative context. The Province (see Table 5) was the only paper that had a high majority of negative KWIC. The Globe and Mail (see Table 6) was the only paper that had a high amount of positive KWIC. While The Globe and Mail is a centrist paper with academic leanings, this finding was not anticipated. I expected The Toronto Star (see Table 8) to have the highest amount of positive KWIC as it is the most socially liberal paper. The other three newspapers had less of a discrepancy between negative and positive KWIC count. It is surprising that there is such a large discrepancy between The Vancouver Province and The Vancouver Sun, regarding positive and negative KWICs, as they are both owned by the same company and it would be expected that their social leanings were aligned. There is much less correlation than expected in terms of left-wing papers and positive KWIC and right-wing papers and negative KWIC counts. However, this observation is based solely on the KWICs alone and not taking into consideration the frameworks that accompanied each term.

Of the 17 KWICs identified, six were used in both sets of data. There was one KWIC exclusively seen in the Taylor data as seen in Table 3 which was inhumane death. There were ten KWICs used exclusively in the Rodriguez data as seen in Table 4 which were 'criminal act,' 'death,' 'good death,' 'legalized euthanasia,' 'murder,' 'mercy-killing,' 'premature death,' 'state killing' and 'voluntary euthanasia'. It is of interest that the majority of the 10 extra KWICs in the Rodriguez data are negative or were used in a negative manner. This corresponds to the general findings that opinions were more favourable in 2012. That there were ten more KWICs used in 
the Rodriguez data suggests that the act of 'medically assisted dying' was less understood and therefore could be defined and redefined by media. The change of 17 KWICs to ten KWICs could also suggest that as understanding of the issue grows there is less flexibility on acceptable terms whether they are negative or positive.

Also analyzed and counted were the terms referring to the actual death of the women. After analysis it was decided that the count for terms referring to Taylor's death were too few to include. Her actual death was only referred to twice, and in those instances it was labelled 'died' and 'death'. This is much different than when Rodriguez passed away as can be seen below in Table 10.

Table 10. Terms Referring to Sue Rodriguez in Newspaper Editorials (February 12-21, 1994)

\begin{tabular}{|c|c|c|c|c|}
\hline Term referring to Sue Rodriguez's Death & Positive & Negative & Neutral & Overall \\
\hline Assisted-Suicide & 2 & 3 & & 5 \\
\hline Death/Died/Die & 4 & 2 & 2 & 8 \\
\hline Doctor-Assisted Suicide & 1 & & & 1 \\
\hline Euphemism Phrases & 7 & & & 7 \\
\hline Help Kill/Killed/Killing & & 2 & & 2 \\
\hline Leaving & & & 1 & 1 \\
\hline Suicide & 1 & 1 & & 2 \\
\hline Walked Away & & & 1 & 1 \\
\hline TOTAL & $\begin{array}{c}15 \\
(55.5 \%)\end{array}$ & $\begin{array}{c}8 \\
(29.5 \%)\end{array}$ & $\begin{array}{c}4 \\
(15 \%)\end{array}$ & $\begin{array}{c}27 \\
(100 \%)\end{array}$ \\
\hline
\end{tabular}

The variety of terms used to refer to Rodriguez's actual passing includes 'assisted suicide', 'died', 'doctor assisted suicide', 'killed', 'leaving', 'suicide', 'walked away’ and a variety of colourful euphemisms. The euphemism phrases were:

- She planned her passage to safety and the other side

- The delicate and quick passing by lethal injection

- She decided to end her life at a time of her choosing 
- He refuses to name the doctor who ended her suffering

- Call for the doctor who provided the death-dealing drugs

- Terminally ill for the right of personal determination for the chosen release of impending pain

- At least 145 suffering people succeeded in ending their lives with medical help

Of the 27 overall terms referring to Rodriguez's death, 15 were positive, eight were negative and four were neutral. Her death was generally perceived to be positive even if the KWIC was found in an overall negative document. This finding seems to indicate that many people were relieved to see her pass peacefully, even if they did not agree with the fact that she broke the law or felt negatively towards assisted death in general.

The KWIC count also analyzed in what context and how many times 'euthanasia' and 'legalized euthanasia' were used incorrectly. 'Euthanasia' and 'legalized euthanasia' were singled out because they were the only KWICs that were repeatedly used incorrectly. Both were constantly used to refer to a patient's death without their consent, whether legal or illegal, as a synonym for 'assisted suicide'. This held true for the documents collected for this paper. Of the 28 times that 'euthanasia' and 'legalized euthanasia' were used in the complete data set - they were used incorrectly in 27 of those instances. As seen in Table 11 and Table 12 there was a wide discrepancy in the instances that 'euthanasia' and 'legalized euthanasia' were used incorrectly.

Table 11. Key Words used incorrectly in all Sue Rodriguez Data

\begin{tabular}{|c|c|c|c|c|}
\hline Term for the Act & Positive & Negative & Neutral & Overall \\
\hline Euthanasia & 1 & 4 & 4 & 9 \\
\hline Legalized Euthanasia & 3 & 8 & 5 & 16 \\
\hline TOTAL & $\begin{array}{c}4 \\
(16 \%) \\
\end{array}$ & $\begin{array}{c}12 \\
(48 \%)\end{array}$ & $\begin{array}{c}9 \\
(36 \%) \\
\end{array}$ & $\begin{array}{c}25 \\
(100 \%)\end{array}$ \\
\hline
\end{tabular}


Table 12. Key Words used incorrectly in all Gloria Taylor Data

\begin{tabular}{|c|c|c|c|c|}
\hline Term for the Act & Positive & Negative & Neutral & Overall \\
\hline Euthanasia & 2 & & & 2 \\
\hline \multicolumn{5}{|l|}{ Legalized Euthanasia } \\
\hline TOTAL & $\begin{array}{c}2 \\
(100 \%)\end{array}$ & & & $\begin{array}{c}2 \\
(100 \%)\end{array}$ \\
\hline
\end{tabular}

'Euthanasia' and 'legalized euthanasia' were used incorrectly 50\% more of the time when in a negative context. The difference in percentage indicates that the use of 'euthanasia' in positive versus negative contexts is not a coincidence. Editorials, using 'euthanasia' in a negative context, could be purposely using 'euthanasia' because of its possible negative connotations and ambiguous meaning. Since 'euthanasia' has stronger negative connotations (Nazi eugenics) than positive (literally, good death) it is avoided by movements supporting 'medically assisted dying'. The ambiguity of the term 'euthanasia' can leave more doubt in the reader's mind, letting them fill in the blanks about what 'euthanasia' is and what it could lead to. Marker and Smith (1996) support this finding. They note, "the word euthanasia is generally avoided in proposals to legalize it.” (p. 83). According to Atwood Gailey (2003), this is an unsurprising result. She notes "a broad spectrum of meanings and definitions have been attached to the word 'euthanasia' throughout history" including "(1) passive, (2) semipassive, (3) semiactive, (4) accidental, (5) suicidal, and (6) active" (p. 135). Unfortunately, regardless of which definition is attached to 'euthanasia' - it is incorrect to use it interchangeably with 'medically assisted dying' - despite their seemingly semantic similarities.

The next step in analysis was to determine which frameworks were used, and with which KWIC were they most commonly paired. The six frameworks used were 'medically assisted dying' legal, 'medically assisted dying' medical, 'medically assisted dying' moral, 'pro-life' legal, 'pro-life' medical and 'pro-life' moral. Identifying the frames was accomplished by 
finding framing devices such as key words, lexical choices, anecdotes, historical examples, appeals and more. For example, lexical choices such as 'decriminalize' or 'legalize' were telling when placed in close proximity to certain KWICs.

The following demonstrates a complete analysis of the editorial "Criminal Charges Would Insult Sue Rodriguez" (February 15, 1994, The Vancouver Sun). The first read for manifest content revealed that this editorial was in favour of Rodriguez, in favour of legalized 'medically assisted dying', and against prosecuting Svend Robinson for his participation. The latent content implied the author was in favour of 'medically assisted dying' and felt the B.C. Court of Appeal failed Rodriguez. I then read for KWICs and other framing devices. This editorial included seven positive KWICs and one neutral KWIC. It twice made reference to legal, 'physician assisted suicide'. The tendency towards a legal frame quickly emerged based on lexical choices alone. The words 'legal', 'judicial' and 'courts' appeared eight times. The editorial also used the terms 'prosecution', 'conviction', 'charges', 'jurisdiction' and 'parliament'. A second framing device identified was the headline - "Criminal Charges Would Insult Sue Rodriguez" - which was a clear indication of both the tone and frame of the editorial. A third identifier was the use of actors; in this case the actors mentioned were Rodriguez, Robinson and B.C. Attorney General Colin Gabelmann. Rodriguez and Robinson were portrayed in a positive manner; Gabelmann was portrayed in a neutral manner. The last identifier was the scene, which was determined as the B.C. Court of appeal. The article also makes a strong emotional appeal to empathy - suggesting that we should feel for Rodriguez and her unendurable suffering. Taking all of the content and framing devices into consideration - it was determined that the editorial used a ML framework. 


\section{Table 13. Number of Frames Found in Documents}

\begin{tabular}{|l|c|}
\hline Frame & Number of times frame was found \\
\hline Medically assisted dying legal (ML) & $25(27 \%)$ \\
\hline Medically assisted dying medical (MM) & $12(13 \%)$ \\
\hline Medically assisted dying moral (MMM) & $27(29 \%)$ \\
\hline \multicolumn{1}{|r|}{ Subtotal } & $\mathbf{6 4}(\mathbf{6 9 \%})$ \\
\hline Pro-life legal (PLL) & $12(13 \%)$ \\
\hline Pro-life medical (PLM) & $5(5 \%)$ \\
\hline Pro-life Moral (PLMM) & $12(13 \%)$ \\
\hline & $\mathbf{2 9 ( 3 1 \% )}$ \\
\hline & Subtotal \\
Total & $\mathbf{9 3 ( 1 0 0 \% )}$ \\
\hline
\end{tabular}

It was determined that a frame was used in 93 separate instances. This meant that of the 44 documents analysed, there were approximately two frames used per document. Most documents only used one or two frames. The highest frame count in one document was 11. Frames in support of 'medically assisted dying' were used more than double the amount that 'pro-life' frames were used. Specifically, frames that favoured 'medically assisted dying' were used $69 \%$ of the time, versus frames that favoured 'pro-life,' which were used in only $31 \%$ of the documents. An example of a frame favouring 'medically assisting dying' can be seen in a letter to the editor entitled “Courts Shouldn't Decide Our Deaths" (February 18, 1994, The Star). The framing devices which made the MMM frame apparent were phrases and lexical choices. In one phrase the author stated, "we take responsibility for our own lives; we should take responsibility for our own deaths." An example of a legal frame favouring 'pro-life' can be seen in an editorial entitled "Assisted Suicide Opens a Pandora's Box on Death" (February 17, 1994, The Vancouver Sun). This frame emerged because of the heavy amount of legal jargon used throughout. The editorial then discussed what can go wrong once 'medically assisted dying' is legalized. The editorial compares the potentially bleak future of Canada to other countries which have already created legislation, and are now sliding down the slippery slope towards a society that kills those with lives not worth living. This editorial used an emotional appeal by way of fear. 
One trend that held true for both 'pro-life' and 'medically assisted dying' frames was that legal and moral frames were much more prominent than medical frames. Overall, legal and moral frames were used 76 times, or in $82 \%$ of the documents. This finding is in stark contrast to the 17 instances that medical frames were used, or in $18 \%$ of the documents. This result deviated from findings in a different study. Atwood Gailey (2003) states "it is significant that medical frames were found to be equally dominant in both pro- and anti- euthanasia news coverage" ( $p$. 123). Despite the high percentage of medical frames found by Atwood Gailey, the circumstances can account for the difference in results. Atwood Gailey was accounting for a generalization of all media coverage of 'medically assisted dying;' whereas this research was focused specifically on documents that occurred during two very public legal battles. The reason for the lack of medical frames is further supported when looking at the definition of medical frames as defined by Atwood Gailey. Atwood Gailey (2003) explains, "medical frames were considered dominant in any story that filtered euthanasia primarily through the viewpoints and values of medical establishments. Specific characteristics of this frame include heavy reliance on medical sources, medical terms, and/or medical ideological positions" (p. 60). There were no editorials from the perspective of the medical community in all the documents analyzed. Medical frames were used, but never as the dominant framework in an article. Further, the circumstances were apt for a high percentage of legal and moral frames. This is because the Rodriguez case was the first of its kind in Canada and the first to experience public debate in both the courtroom and the public sphere.

After the frames were determined, I counted which frames were used with which KWICs - and whether the KWICs were used in a positive, negative or neutral manner. The results can be seen in Tables 14, 15 and 16. 
Table 14. Instances of Frames Occurring with Positive KWICs

\begin{tabular}{|l|l|l|l|l|l|l|}
\hline & PLL & PLM & PLMM & ML & MM & MMM \\
\hline Term for the Act & & & & & 1 & \\
\hline Active Euthanasia & & & & & & \\
\hline $\begin{array}{l}\text { Assisted } \\
\text { Suicide/Legally } \\
\text { Assisted Suicide }\end{array}$ & & & & 15 & 5 & 7 \\
\hline Criminal Act & & & & & & \\
\hline Death & & & & & \\
\hline $\begin{array}{l}\text { Die with } \\
\text { Dignity/Right to Die }\end{array}$ & & & & 4 & & 7 \\
\hline Euthanasia & & & 1 & 1 & 2 \\
\hline $\begin{array}{l}\text { Good } \\
\text { Death/Compassionate } \\
\text { Death }\end{array}$ & & & & & & \\
\hline Inhumane Death & & & & & & \\
\hline Kill/Killed & & & & & & \\
\hline Legalized Euthanasia & & & & & & \\
\hline Manslaughter/Murder & & & & & & \\
\hline $\begin{array}{l}\text { Mercy- } \\
\text { Killing/Terminating } \\
\text { the Patient }\end{array}$ & & & & & & \\
\hline $\begin{array}{l}\text { Physician Assisted } \\
\text { Suicide/Doctor } \\
\text { assisted suicide }\end{array}$ & & & & & & \\
\hline Premature Death & & & & & & \\
\hline State Killing & & & & & & \\
\hline Suicide & & & & & & \\
\hline Voluntary Euthanasia & & & & & & \\
\hline
\end{tabular}

Unsurprisingly, KWICs used in a positive manner were most often found in the frames ML, MM and MMM. For example, positive KWICs including 'physician assisted suicide', 'good death', and 'assisted suicide' were all found exclusively in the frames ML, MM and MMM. Similarly, KWICs used in a negative manner were most often found in the frames PLL, PLM and PLMM. For example, negative KWICs including 'state killing', 'murder' and 'kill' were all found exclusively in the frames PL, PLM and PLMM. 
Table 15. Instances of Frames Occurring with Negative KWICs

\begin{tabular}{|c|c|c|c|c|c|c|}
\hline & PLL & PLM & PLMM & ML & MM & MMM \\
\hline \multicolumn{7}{|l|}{ Term for the Act } \\
\hline \multicolumn{7}{|l|}{ Active Euthanasia } \\
\hline $\begin{array}{l}\text { Assisted } \\
\text { Suicide/Legally } \\
\text { Assisted Suicide }\end{array}$ & 11 & 5 & 2 & & 1 & \\
\hline Criminal Act & 1 & & & & & \\
\hline \multicolumn{7}{|l|}{ Death } \\
\hline $\begin{array}{l}\text { Die with } \\
\text { Dignity/Right to Die }\end{array}$ & 1 & & 1 & & & \\
\hline Euthanasia & 4 & & 3 & 1 & & \\
\hline \multicolumn{7}{|l|}{$\begin{array}{l}\text { Good } \\
\text { Death/Compassionate } \\
\text { Death }\end{array}$} \\
\hline Inhumane Death & & & & & 1 & \\
\hline Kill/Killed & 5 & 5 & & & & 1 \\
\hline Legalized Euthanasia & 3 & & & & & \\
\hline Manslaughter/Murder & 1 & 3 & & & & \\
\hline $\begin{array}{l}\text { Mercy- } \\
\text { Killing/Terminating } \\
\text { the Patient }\end{array}$ & 3 & 1 & 1 & & 2 & \\
\hline $\begin{array}{l}\text { Physician Assisted } \\
\text { Suicide/Doctor } \\
\text { assisted suicide }\end{array}$ & 1 & 1 & & & & 1 \\
\hline Premature Death & 1 & & & & & \\
\hline State Killing & 2 & & & & & 1 \\
\hline Suicide & 1 & 1 & 1 & & & \\
\hline Voluntary Euthanasia & 1 & & & & & \\
\hline
\end{tabular}

Interestingly, negative KWICs were more likely to be found used in 'positive' frames than positive KWICs being found in 'negative' frames. Positive KWICs were only used 3 times in the PLL, PLM and PLMM frames; whereas negative KWICs were used 9 times in the ML, MM and MMM frames. This discrepancy becomes even more noticeable when the amount of negative versus positive KWICs is compared. There are far less negative KWICs than positive KWICs. This shows that, although there are less negative KWICs overall, they are used over a wider spectrum of frames. 
Table 16. Instances of Frames Occurring with Neutral KWICs

\begin{tabular}{|l|l|l|l|l|l|l|}
\hline & PLL & PLM & PLMM & ML & MM & MMM \\
\hline Term for the Act & & & & & & \\
\hline Active Euthanasia & & & & & & 3 \\
\hline $\begin{array}{l}\text { Assisted } \\
\text { Suicide/Legally } \\
\text { Assisted Suicide }\end{array}$ & 1 & 1 & & 5 & & \\
\hline Criminal Act & & & & & & \\
\hline Death & & & & & & \\
\hline $\begin{array}{l}\text { Die with } \\
\text { Dignity/Right to Die }\end{array}$ & 1 & & & & & \\
\hline Euthanasia & & & & & & \\
\hline $\begin{array}{l}\text { Good } \\
\text { Death/Compassionate } \\
\text { Death }\end{array}$ & & & & & & \\
\hline Inhumane Death & & & & & & \\
\hline Kill/Killed & & & & & & \\
\hline Legalized Euthanasia & 1 & & & & & \\
\hline Manslaughter/Murder & & & & & & \\
\hline $\begin{array}{l}\text { Mercy- } \\
\text { Killing/Terminating } \\
\text { the Patient }\end{array}$ & & 1 & & & & \\
\hline $\begin{array}{l}\text { Physician Assisted } \\
\text { Suicide/Doctor } \\
\text { assisted suicide }\end{array}$ & & & & & & \\
\hline Premature Death & & & & & & \\
\hline State Killing & & & & & & \\
\hline Suicide & 1 & & & & & \\
\hline Voluntary Euthanasia & & & & & & \\
\hline
\end{tabular}

Also to note are which particular KWICs were found in unexpected frames. The only positive KWIC used in PLL, PLM and PLMM was 'right to die'/'die with dignity'. In two of those occurrences it was written with quotations as 'right to die' - inferring that it is not actually a right. Alternatively, there were a wide variety of negative KWICs found in the frames ML, MM and MMM including 'assisted suicide', 'euthanasia', 'inhumane death', 'killed', 'mercy-killing' and 'state killing'. This finding could imply that authors against 'medically assisted dying' were hesitant to use any term which may accidently be construed as in support of the act; whereas authors for 'medically assisted dying' may be open to debate both sides of the argument using a 
variety of terms in their opinion pieces. This idea is further supported when comparing Table 2 and Table 13. These results reveal that, although there was an almost even amount of positive and negative KWIC's used across all documents, there were a much higher percentage of frames used to argue in favour of 'medically assisted dying'.

The data became more persuasive after comparing which frames were used in which publications - and how many times each occurred. For the most part these results correlated with positive, negative and neutral KWIC counts. The Vancouver Province which had the highest amount of negative KWICs was determined to have used the frames PLL, PLM and PLMM most often. Similarly, The Globe and Mail which had the highest amount of positive KWICs was determined to have used the frames ML, MM and MMM most often. The Vancouver Sun and The Toronto Star used a somewhat equal amount of both 'pro-life' and pro-'medically assisted dying' frames. The Toronto Sun was the one paper for which the results did not correlate between the KWIC count and frame count. The paper had an almost even spread between neutral, positive and negative KWIC, yet the frames used are overwhelmingly ML, MM and MMM. The results for the online postings were even clearer. With very little exception the numbers correlated between negative KWICs and the frames PLL, PLM and PLMM and positive KWICs and the frames ML, MM and MMM. This suggests that there is a correlation between how a KWIC is used and in which frame that KWIC can be found. This data also suggests that some of the news outlets can be classified as more positive or more negative; specifically The Province and The Globe and Mail. Overall, it seems as though 'medically assisted dying' is framed in a positive manner more than a negative manner. But when it is framed in a negative manner it is limited to certain news outlets. 
Table 17. Number of Frames Found in Each Publication

\begin{tabular}{|l|c|c|c|c|c|c|}
\hline \multicolumn{1}{|c|}{ Publication } & PLL & PLM & PLMM & ML & MM & MMM \\
\hline The Vancouver Sun & 4 & & 4 & 7 & 1 & 5 \\
\hline The Vancouver Province & 6 & 1 & 4 & & 1 & 4 \\
\hline The Globe and Mail & 1 & & 1 & 4 & 2 & 7 \\
\hline The Toronto Star & & 2 & 1 & 3 & 5 & 3 \\
\hline The Toronto Sun & 1 & & & 2 & 1 & 3 \\
\hline CBC Online & & 2 & & 4 & 1 & 2 \\
\hline The National Post Online & & 1 & 1 & & 1 & \\
\hline The Globe and Mail Online & & & & 3 & & \\
\hline The Toronto Sun & & & & 2 & & 3 \\
\hline \multicolumn{1}{r|}{ Total } & $\mathbf{1 2}$ & $\mathbf{5}$ & $\mathbf{1 2}$ & $\mathbf{2 5}$ & $\mathbf{1 2}$ & $\mathbf{2 7}$ \\
\hline
\end{tabular}

The results seen in Table 17 indicate that there may be a connection between the frames and the KWICs used in the coverage of the Rodriguez and Taylor cases. This finding supports the idea that it is a more than a coincidence that particular KWICs appear within certain frames. Weber (1985) states "KWIC lists provide systematic information that is helpful in determining whether the meaning of particular words is dependent upon their use in certain phrases or idioms." (p. 47). Scott and Tribble (2006) agree "we can use keywords to identify major themes in the news" (p. 168). The results of this research support the idea that particular KWICs are indicative of the particular frames they are found within. That there seems to be a correlation between KWICs and frames made it easier to establish where certain types of arguments were being made. The correlation between KWICs and frames answered the primary research question as I was able to see the arguments being made on both sides of the debate. Once I answered the primary research question by identifying the arguments used on both sides of the debate, I was able to compare the arguments used in 1994 and 2012. By comparing the time periods I was able to establish how arguments have changed from the Rodriguez to Taylor time period. From the above findings, there are two principal observations from the data collected. The first is that the amount of positive KWICs doubled in use from 1994 to 2012. The second observation is that 
'euthanasia' and 'legalized euthanasia' were only used incorrectly in two instances in 2012, rather than in 25 instances in 1994. These two observations suggest that KWICs are changing and terms are not only becoming more supportive of 'medically assisted dying,' but that the terminology is being used correctly more often. While this finding does not prove that opinions are changing on the whole, it does suggest KWICs are changing, and as previously stated, there seems to be a correlation between a KWIC and the frame that KWIC is found in. Based on this evidence it is possible that arguments are changing and are possibly becoming more favourable towards 'medically assisted dying'.

\section{Conclusion}

This MRP was interested in analyzing and understanding the language used in editorial coverage of the Sue Rodriguez and Gloria Taylor cases. The research was carried out by using content analysis and KWICs to identify frames and arguments used on both sides of the debate. Due to availability, editorials were used for the Rodriguez data and online comments were used for the Taylor data. It was unexpected but interesting that the data I was anticipating trouble finding was readily available, and the data I thought would be easily collected was not. There were plenty of editorials twenty years ago, but none in the past few years. In this case, the variation in available data might speak to both the topic at hand and the circumstances in which they occurred. Although there were not even two full decades between the cases, there were different conditions under which these women's stories emerged. In the early 1990's, 'euthanasia' and 'medically assisted dying' were newsworthy topics for a few reasons; primarily, the rise of Dr. Kevorkian and numerous American states voting to change 'assisted suicide' legislation. Dr. Kevorkian rose to prominence in 1989 after very publicly assisting Janet Adkins with her death. Over the next decade, he claimed to assist 130 people and was in and out of 
courtrooms for murder many times. Dr. Kevorkian made 'medically assisted dying' less taboo for media to cover. At the same time, California, Washington and Oregon were all trying to change their 'assisted suicide' legislation in favour of legalizing 'medically assisted dying'. The first few attempts failed but Oregon would be the first state to legalize 'medically assisted dying' in 1994. What Dr. Keverkian made public, Oregon made legal. However, since the 1990s this topic has become less 'newsworthy,' which led to a decrease in available documents. The variation in available documents reveals not only the possible changing of opinion towards 'medically assisted dying', but also the ways in which we read and respond to news.

By identifying the frames and KWICs used in both case studies it became possible to compare the two. Comparing the two case studies led to three findings of interest. The first finding was related specifically to language. While the amount of documents for each time period varied, one observation that emerged because of KWICs held true for both sets of data. Positive KWICs were generally found with positive frames and negative KWICs were generally found with negative frames. This was generally the case regarding documents as a whole. Of the 17 KWICs used, there was an almost even split between negative and positive use. This is interesting as there was a significantly higher amount of positive frames. This suggests that in the documents that used negative frames, there was a particularly high KWIC count. Negative KWICs were also associated with incorrect language. The terms 'euthanasia' and 'legalized euthanasia' were used incorrectly $50 \%$ more of the time in a negative context. Further, the data collected for this paper revealed that positive KWICs were used over twice as much in 2012 as they were in 1994. There were also no neutral KWIC or frames used in 2012. This may suggest that Canadians are making firm decisions about where they stand on the issue. The second main finding is related to frames. Overall, $64 \%$ of the frames were used in a positive manner 
supporting 'medically assisted dying'. Additionally, there were a much higher percentage of legal and moral frames used than medical frames. The single highest frame count was medically assisted dying moral (MMM). The single lowest frame count was pro-life medical (PLM). This suggests that frames favour both 'medically assisted dying' and moral arguments. The importance of frames cannot be underestimated. Frames shape our coherence and clarity of an issue. How we define and frame 'medically assisted dying' plays a part in our understanding of the matter.

The third finding was related to news organizations. It seems as though on a whole opinions have become more favourable, which may or may not be reflected within individual media organizations. Unfortunately, because of a limited number of available documents from 2012, I was unable to truly compare if publications kept their stance similar over the 18-year period. If anything, the opinion of the editors surfaced more than the stance of the newspapers. Although, an editor's opinions likely represents the newspaper he or she works for. The Globe and Mail and the Toronto Sun were the only two papers which had documents included from both 1994 and 2012. In 1994, both papers included frames that were both 'pro-life' and pro'medically assisted dying'. In 2012, both papers used frames that were exclusively favoring 'medically assisted dying'. This is barely enough evidence to suggest anything one way or the other. However, it is of interest and may hint towards a pattern. An area of further research could include analyzing a wider range of Canadian newspapers in both time periods to see if changing attitudes is a potential pattern.

As stated earlier, the circumstances surrounding each case study varied greatly. Rodriguez was fighting in court and receiving media coverage at a time in which 'medically 
assisted dying' was extremely newsworthy. The conditions and context with which Taylor was placed are less clear. Public favour has never before been so high for 'medically assisted dying'. In a 2011 Canadian poll, 70\% of Canadians favoured legalizing 'medically assisted dying' (Farewell Foundation, 2011). Yet its place in the media seems to have been diminished. However, whether this is due to lack of support or perhaps lack of newsworthiness (because it's generally accepted now) is unclear. The growing public support for 'medically assisted dying' in Canada, as concluded by polls, is supported by the findings of this paper.

Analyzing documents through KWICs helped reveal how language is negotiable and malleable as a tool of rhetoric. As there was such a high correlation between KWIC and frame use, it certainly seems as though word choice was never arbitrary in the analyzed documents. Word choice always has the potential to influence opinion as language is steeped with rhetoric. The use of rhetorical strategies in the analyzed documents was apparent on both sides of the debate. The documents analyzed revealed these shared strategies included lexical choices, framing devices and emotional appeals. The power of emotional appeals cannot be overlooked. Aristotle wrote that all emotions need to be identified to correctly appeal to their audience. Of the fourteen emotions he identified -- fear, enmity, pity and kindness -- are the ones that are being appealed to in the 'medically assisted dying' debate. Interestingly, both sides use all four emotions but appeal to them through vastly different arguments. Like emotional appeals, both sides used lexical choice and framing devices to create meaning. In the instance of 'medically assisted dying' language always takes on meaning, sometimes despite author intentions. Atwood Gailey (2003) explains that "naming or defining a problem not only privileges certain interpretations, but establishes the existence of a social problem and, once established, determines its relevancy or irrelevancy" (p. 133). In each of these cases, just by naming the act of 
'medically assisted dying', the writer creates meaning and context for the reader. Naming the act of 'medically assisted dying' has the potential to problematize the issue in a certain way, whether the author is expressing a lack of support for the women or comparing medically assisted dying to Nazi eugenics. However, bias almost always shows through whether or not the language tries to be neutral or is charged full of meaning. The cases of Sue Rodriguez and Gloria Taylor demonstrate how much power the media has over choosing the terms, dividing the sides and drawing the battle lines. 


\section{Appendix A}

\section{Newspaper Editorials Collected}

\section{(Derived from a Sample of Canadian English-language Newspapers)}

1. Our View (The Province, 15/02/94)

2. Making a Hero of Rodriguez for Giving Up (The Province, 15/02/94)

3. Robinson's Role Has Been Selfless (The Province, 17/02/94)

4. A License to Kill (The Province, 18/02/94)

5. Coming Too Close to Murder (The Province, 18/02/94)

6. Righteous Living Making Decisions for the Dying (The Province, 20/02/94)

7. Nurse Death Failed Us (The Vancouver Sun, 15/02/94)

8. 'She Wanted me....with her at time of death' (The Vancouver Sun, 15/02/94)

9. Criminal Charges Would Insult Sue Rodriguez (The Vancouver Sun, 15/02/94)

10. Assisted Suicide Opens a Pandora's Box on Death (The Vancouver Sun, 17/02/94)

11. Rodriguez Physician Should be Left Alone (The Vancouver Sun, 17/20/94)

12. A Battle to - and for - the Death (The Vancouver Sun, 18/20/94)

13. Who are Heroes, Villains in Sue Rodriguez Tale? (The Vancouver Sun, 19/20/94)

14. In Need of Assistance on Euthanasia (The Globe and Mail, 15/02/94)

15. A Death that turns a Complex and Emotional Issue over to Parliament, (The Globe and Mail, 18/02/94)

16. Getting Parliament to Act on Suicide (The Globe and Mail, 16/02/94)

17. Ask Yourself, Whose Life is this? (The Globe and Mail, 21/02/94)

18. Give Terminally Ill the Right to Die (The Toronto Star, 15/02/94)

19. Court's Shouldn't Decide our Deaths (The Toronto Star, 18/02/94)

20. The Politics of Dying (The Toronto Star, 19/02/94)

21. It's Time (The Toronto Sun, 15/02/94)

22. Let's Talk (The Toronto Sun, 17/02/94)

23. The Dangers of Self-Determination (The Toronto Sun, 19/02/94) 


\section{Appendix B}

\section{Online Comments Collected}

\section{(Derived from a Sample of English-language Online Newspapers)}

1. My sincerest sympathies...Gloria was a heroic woman, and this Canadian appreciated her struggle on all Canadians behalf to die with dignity and at the time of their own choosing. (CBC, 05/10/12)

2. Gloria Taylor, was a tireless crusader fighting for the laws to be changed to allow people who wish assisted suicide to end their mortal life. I believe, because of Ms. Taylor; soon all the laws will be changed in favour of assisted suicide for those who wish or want that service. I have always believed like Gloria; when you are beyond repair and not much hope of any quality recovery - the choice to stay or go should be honoured and respected by the law for that person requesting such a service. Hanging on when your life has no quality and lacks majority bodily function. Yes, by all means if the person has good mental facilities; that person should be granted their wish by law. Thank you Gloria Taylor, for your efforts and tireless endeavors on this subject. You are a great humanitarian - trying to help others when they really need that ultimate help. May you be in a better place today; young, strong, happy and healthy again. (CBC, 05/10/12)

3. I hope she had some good pain control because a perforated colon is very painful. What a courageous woman she was. Fighting for physician assisted suicide till the end. A peaceful rest to you my good woman. (CBC, 05/10/12)

4. When are we, as a society going to allow people who are terminally ill and suffering from dehabiliating pain the right to end their life. Could we please call it euthanasia and not assisted suicide. Euthanasia to me, seems like a more compassionate word to the ending of a person or an animals life. (CBC, 05/10/12)

5. For those of you who have posted comments that mention that taxpayers should not have to fund medically assisted suicide: Have you ever had a friend or relative waste away for weeks in a hospice? How many taxpayer dollars are spent taking care of people for days, sometimes weeks, in a hospice as they await death in total agony? I would argue that assisted suicide is not only humane, but also much cheaper. (CBC, 05/10/12)

6. Gloria Taylor will be remembered fondly by those who watched her champion a fight for the rights of those of us that aspire to die with dignity. (CBC, 05/10/12)

7. At least her body had control of her life that cannot be said about all the hypocrites that all thought they have never been in her position tried to control her conscious decisions. As least now she will be in peace with herself I hope that can not be said about the opponents to assisted suicide. (CBC, 05/10/12) 
8. Assisted suicide=eugenics, one step away from killing so called "undesirables". (CBC, $05 / 10 / 12)$

9. Sincere condolences to Ms. Taylor's family and friends. She was so courageous in her fight. There is some irony though in her unexpected death in that God truly does have a plan for all of us. I watched my own parents die a dignified death - neither would have requested assisted suicide. Death is not easy for any of us, but it will for all without our assistance. As a nurse, my job is to help people heal or help provide them a dignified passing. That could happen without assisted suicide. (CBC, 05/10/12)

10. Thank you Gloria for taking the time and energy to fight for what isn't a privilege for those who face a life threatening disease. Palliative dehydration is not a humane practice, although it is widely practiced. On behalf of my mother, who died an inhumane death, thank you and my deepest condolences to your family. (The National Post, 05/10/12)

11. There you go. Nature took it's natural course, and no doctor had to intervene and kill her. (The National Post, 05/10/12)

12. Thankfully God took her before she took herself. (The National Post, 05/10/12)

13. Thank you Gloria, for your quiet strength in challenging this country's immoral and unethical restrictions on assisted suicide. The present government, in trying to negate this right, has shown that it has no grasp of the issues facing those whose quality of life is destroyed by an incurable and degenerative illness. (The Globe and Mail, 05/10/12)

14. Ms Taylor has giving Canadians the right to choose, for that she should be commended. Thank you. (The Globe and Mail, 05/10/12)

15. Poll after poll shows that a majority of Canadians support a death with dignity law. Yet Harper and his Tories pander to a right wing religious fringe and a palliative care "death" industry with a vested economic interest. Justin Trudeau and the Liberals could really make a comeback if they had the balls to take ownership of this social issue. This along with legalizing and taxing marijuana. You know --- sane policies that the average Canadian supports. (The Globe and Mail, 05/10/12)

16. Sad right-to-die advocate Gloria Taylor passed away. Complex issue but should allow a choice if one has a terminal illness. Who decides when. (The Toronto Sun, 05/10/12)

17. Ironically, right-to-die advocate Gloria Taylor discovers that her death comes at a time NOT of her choosing. (The Toronto Sun, 05/10/12)

18. gloria taylor she fought to have a doc assisted suicide, so she could die with dignity. (The Toronto Sun, 05/10/12)

19. She fought for the better of all canadians. Assisted-suicide activist Gloria Taylor dies from infection in B.C. (The Toronto Sun, 05/10/12) 
20. Sadly, not the way she intended. "Right to Die" activist Gloria Taylor dies. (The Toronto Sun, 05/10/12)

21. Woman who fought to overturn assisted-suicide law dies . Gloria \#Taylor died unexpectedly, says \#BC rights group" RIP Gloria. Thank you! (The Toronto Sun, 05/10/12) 


\section{Appendix C:}

KWICs used in Rodriguez Data

(Derived from a Sample of Canadian English-language Newspapers)

Table 5. Key Words used in The Province (February 12-21, 1994)

\begin{tabular}{|c|c|c|c|c|}
\hline Term for the Act & Positive & Negative & Neutral & Overall \\
\hline Active Euthanasia & 1 & & & 1 \\
\hline Assisted Suicide/Legally Assisted Suicide & 1 & 9 & 2 & 12 \\
\hline Criminal Act & & 1 & & 1 \\
\hline \multicolumn{5}{|l|}{ Death } \\
\hline \multicolumn{5}{|l|}{ Die with Dignity/Right to Die } \\
\hline Euthanasia & 1 & 2 & 1 & 4 \\
\hline \multicolumn{5}{|l|}{ Good Death/Compassionate Death } \\
\hline Kill/Killed & & 7 & & 7 \\
\hline Legalized Euthanasia & & 3 & 1 & 4 \\
\hline Manslaughter/Murder & & 4 & & 4 \\
\hline Mercy-Killing/Terminating the Patient & & 2 & 1 & 3 \\
\hline $\begin{array}{l}\text { Physician Assisted Suicide/Doctor assisted } \\
\text { suicide }\end{array}$ & & 1 & & 1 \\
\hline \multicolumn{5}{|l|}{ Premature Death } \\
\hline \multicolumn{5}{|l|}{ State Killing } \\
\hline Suicide & 1 & & 1 & 2 \\
\hline Voluntary Euthanasia & & 1 & & 1 \\
\hline TOTAL & $\begin{array}{c}4 \\
(10 \%)\end{array}$ & $\begin{array}{c}30 \\
(75 \%)\end{array}$ & $\begin{array}{c}6 \\
(15 \%)\end{array}$ & $\begin{array}{c}40 \\
(100 \%)\end{array}$ \\
\hline
\end{tabular}

Table 6. Key Words used in The Vancouver Sun (February 12-21, 1994)

\begin{tabular}{|l|c|c|c|c|}
\hline Term for the Act & Positive & Negative & Neutral & Overall \\
\hline Active Euthanasia & & & & \\
\hline Assisted Suicide/Legally Assisted Suicide & 7 & 4 & 1 & $\mathbf{1 2}$ \\
\hline Criminal Act & & & & \\
\hline Death & 2 & & & $\mathbf{2}$ \\
\hline Die with Dignity/Right to Die & 2 & 2 & & $\mathbf{4}$ \\
\hline Euthanasia & 1 & 2 & 1 & $\mathbf{4}$ \\
\hline Good Death/Compassionate Death & & & & \\
\hline Kill/Killed & & 1 & & $\mathbf{1}$ \\
\hline Legalized Euthanasia & & & & \\
\hline Manslaughter/Murder & & & & \\
\hline Mercy-Killing/Terminating the Patient & & 2 & & $\mathbf{2}$ \\
\hline $\begin{array}{l}\text { Physician Assisted Suicide/Doctor assisted } \\
\text { suicide }\end{array}$ & 5 & 1 & & $\mathbf{6}$ \\
\hline
\end{tabular}




\begin{tabular}{|c|c|c|c|c|}
\hline Premature Death & & 1 & & 1 \\
\hline State Killing & & 1 & & 1 \\
\hline Suicide & 1 & & & 1 \\
\hline \multicolumn{5}{|l|}{ Voluntary Euthanasia } \\
\hline TOTAL & $\begin{array}{c}18 \\
(53 \%)\end{array}$ & $\begin{array}{c}14 \\
(41 \%) \\
\end{array}$ & $\begin{array}{c}2 \\
(6 \%) \\
\end{array}$ & $\begin{array}{c}34 \\
(100 \%) \\
\end{array}$ \\
\hline
\end{tabular}

Table 7. Key Words used in The Globe and Mail (February 12-21, 1994)

\begin{tabular}{|c|c|c|c|c|}
\hline Term for the Act & Positive & Negative & Neutral & Overall \\
\hline \multicolumn{5}{|l|}{ Active Euthanasia } \\
\hline Assisted Suicide/Legally Assisted Suicide & 7 & & 5 & 12 \\
\hline \multicolumn{5}{|l|}{ Criminal Act } \\
\hline \multicolumn{5}{|l|}{ Death } \\
\hline \multicolumn{5}{|l|}{ Die with Dignity/Right to Die } \\
\hline Euthanasia & 2 & & 4 & 6 \\
\hline Good Death/Compassionate Death & 4 & & & 4 \\
\hline Kill/Killed & & 1 & & 1 \\
\hline \multicolumn{5}{|l|}{ Legalized Euthanasia } \\
\hline \multicolumn{5}{|l|}{ Manslaughter/Murder } \\
\hline Mercy-Killing/Terminating the Patient & & & 1 & 1 \\
\hline $\begin{array}{l}\text { Physician Assisted Suicide/Doctor assisted } \\
\text { suicide }\end{array}$ & 3 & & 2 & 5 \\
\hline \multicolumn{5}{|l|}{ Premature Death } \\
\hline State Killing & & 2 & & 2 \\
\hline Suicide & 2 & 1 & 1 & 4 \\
\hline \multicolumn{5}{|l|}{ Voluntary Euthanasia } \\
\hline TOTAL & $\begin{array}{c}18 \\
(51.5 \%)\end{array}$ & $\begin{array}{c}4 \\
(11.5 \%)\end{array}$ & $\begin{array}{c}13 \\
(37 \%) \\
\end{array}$ & $\begin{array}{c}35 \\
(\mathbf{1 0 0 \%}) \\
\end{array}$ \\
\hline
\end{tabular}

Table 8. Key Words used in The Toronto Star (February 12-21, 1994)

\begin{tabular}{|l|c|c|c|c|}
\hline Term for the Act & Positive & Negative & Neutral & Overall \\
\hline Active Euthanasia & & & & \\
\hline Assisted Suicide/Legally Assisted Suicide & 3 & & & $\mathbf{3}$ \\
\hline Criminal Act & & & & \\
\hline Death & & & & \\
\hline Die with Dignity/Right to Die & 2 & & & $\mathbf{2}$ \\
\hline Euthanasia & 2 & 3 & 2 & $\mathbf{7}$ \\
\hline Good Death/Compassionate Death & & & & \\
\hline Kill/Killed & & & & \\
\hline Legalized Euthanasia & & & & \\
\hline Manslaughter/Murder & & & & \\
\hline Mercy-Killing/Terminating the Patient & & 3 & 1 & $\mathbf{4}$ \\
\hline
\end{tabular}




\begin{tabular}{|l|c|c|c|c|}
\hline $\begin{array}{l}\text { Physician Assisted Suicide/Doctor assisted } \\
\text { suicide }\end{array}$ & 3 & & 3 & \\
\hline Premature Death & & & & \\
\hline State Killing/Legal Suicide & & & & \\
\hline Suicide & 1 & & 1 & $\mathbf{2}$ \\
\hline Voluntary Euthanasia & & & & \\
\hline \multicolumn{1}{|c|}{ TOTAL } & $\begin{array}{c}\mathbf{1 1} \\
(\mathbf{5 2 . 5 \%})\end{array}$ & $\begin{array}{c}\mathbf{6} \\
\mathbf{( 2 8 . 5 \% )}\end{array}$ & $\begin{array}{c}\mathbf{4} \\
\mathbf{( 1 9 \% )}\end{array}$ & $\begin{array}{c}\mathbf{2 1} \\
(\mathbf{1 0 0 \%})\end{array}$ \\
\hline
\end{tabular}

Table 9. Key Words used in The Toronto Sun (February 12-21, 1994)

\begin{tabular}{|l|c|c|c|c|}
\hline Term for the Act & Positive & Negative & Neutral & Overall \\
\hline Active Euthanasia & & & & \\
\hline Assisted Suicide/Legally Assisted Suicide & 3 & & & $\mathbf{4}$ \\
\hline Criminal Act & & & & \\
\hline Death & & & & \\
\hline Die with Dignity/Right to Die & & 1 & & $\mathbf{1}$ \\
\hline Euthanasia & & & & \\
\hline Good Death/Compassionate Death & & & & \\
\hline Kill/Killed & & & & \\
\hline Legalized Euthanasia & & & & \\
\hline Manslaughter/Murder & & & & $\mathbf{5}$ \\
\hline Mercy-Killing/Terminating the Patient & 1 & 1 & 3 & \\
\hline $\begin{array}{l}\text { Physician Assisted Suicide/Doctor assisted } \\
\text { suicide }\end{array}$ & & & & \\
\hline Premature Death & & & & $\mathbf{1 1}$ \\
\hline State Killing/Legal Suicide & & 1 & & $\mathbf{( 1 0 0 \% )}$ \\
\hline Suicide & & & & \\
\hline Voluntary Euthanasia & $\mathbf{4}$ & $\mathbf{3}$ & $\mathbf{4}$ & $\mathbf{( 3 6 . 5 \% )}$ \\
\hline
\end{tabular}




\section{References}

Armstrong, E.M., Carpenter, D.P., \& Hojnacki, M. (2006). Whose Death Matter? Mortality, Advocacy and Attention to Disease in Mass Media. [Electronic Version]. Journal of Health Politics, Policy and Law, 31, 729-772.

Ashipu, K.B.C. (2013). A Rhetorical Analysis of Selected Editorials of Newswatch and Tell Magazine. [Electronic Version]. Studies in Literature and Language, 16, 48-53.

Atwood Gailey, E. (2003). Write to Death: News Framing of the Right to Die Conflict, from Quinlan's Coma to Kevorkian's Conviction. London: Praeger.

Bonyadi, A. (2010). The Rhetorical Properties of the Schematic Structures of Newspaper Editorials: A Comparative Study of English and Persian Editorials. [Electronic Version]. Discourse and Communication, 4, 323-342.

Borchers, T. (2006). Rhetorical Theory: An Introduction. Belmont: Thomson Wadsworth.

Caplan, A.L., \& Turow, J. (2004). Taken to Extremes: Newspapers and Kevorkian's Televised Euthanasia Incident. In L.D. Friedman (Ed.), Cultural Sutures: Medicine and Media (pp. 36-54). Durham: Duke University Press.

Chang, C. (2009). "Being Hooked" by Editorial Content. [Electronic Version]. Journal of Advertising, 38, 21-33.

Clarke, J.N. (2005). Death Under Control: the Portrayal of Death in Mass Print Language Magazines in Canada. [Electronic Version]. Omega: Journal of Death and Dying, 52, 153-167.

Dey, A. K. (2001). Understanding and Using Context. [Electronic Version]. Personal and Ubiquitous Computing, 5, 4-7.

Dysart, D. (2000). Narratives and Values: The Rhetoric of the Physician Assisted Suicide Debate. [Electronic Version]. New Jersey Journal of Communication, 8, 155-172.

Forum Research Inc. (2011, December 16). New poll finds strong majority support for physician-assisted suicide for the terminally ill. Retrieved from http://farewellfoundation.ca/wordpress/wp-content/uploads/2011/12/Assisted-Suicide-inCanada-Forum-Research-2011121611.pdf

Haller, B., \& Ralph, S. (2001). Not Worth Keeping Alive? News Framing of Physician Assisted Suicide in the United States and Great Britain. [Electronic Version]. Journalism Studies, 2, 407421.

Hansen, A., Cottle, S., Negrine, R. \& Newbold, C. (1998). Mass Communication Research Methods. New York: New York University Press. 
Hynds, E.C. (1990). Changes in Editorials: A Study of Three Newspapers, 155-1985. [Electronic Version]. Journalism Quarterly, 67, 302.

Jasinski, J. (2001). Sourcebook on Rhetoric: Key Concepts in Contemporary Rhetorical Studies. London: Sage Publications.

Joslyn, M.R., \& Haider-Markel, D.P. (2002). Framing Effects on Personal Opinion and Perception of Public Opinion: The Cases of Physician Assisted Suicide and Social Security. [Electronic Version]. Social Science Quarterly, 83, 690-706.

Kawinsky, R. (1998). Framing Life and Death: Physician-Assisted Suicide and the New York Times from 1991 to 1996. [Electronic Version]. Journal of Communication Inquiry, 22, 93-112.

Koch, T. (2004). The Difference That Difference Makes: Bioethics and the Challenges of "Disability". [Electronic Version]. Journal of Medicine and Philosophy, 29, 697-716.

Krippendorff, K. (2004). Content Analysis: An Introduction to Its Methodology (2 ${ }^{\text {nd }}$ ed.). London: Sage Publications.

Kuypers, J.A. (2009). Rhetorical Criticism: Perspectives in Action. Virginia: Lexington Books.

Kuypers, J.A. (2010). Framing Analysis from a Rhetorical Perspective. In P. D’Angelo \& J.A. Kuyper (Eds.), Doing News Framing Analysis: Empirical and Theoretical Perspectives (pp. 286311). New York: Routledge.

Lindlof, T.R., \& Taylor, B.C. (2011). Qualitative Communication Research Methods $\left(3^{\text {rd }}\right.$ Ed.). Los Angeles: SAGE Publications.

Littlejohn, S.W., \& Foss, K.A. (2008). Theories of Human Communication $\left(^{\text {th }}\right.$ Ed.). Belmont: Thomas Wadsworth.

Lowy, F.H., Sawyer, D.M., \& Williams, J.R. (1993). Canadian Physicians and Euthanasia. Ottawa: Canadian Medical Association.

McCluskey, M., \& Hmielowski, J. (2011). Opinion Expression During Social Conflict: Comparing Online Reader Comments and Letters to the Editor. [Electronic Version]. Journalism, 13, 303-319.

McKenzie, S. (2005). Death: The New Pornography. [Electronic Version]. Screen Education, 39, 94-97.

Marker, R.L., \& Smith, W.J. (1996). The Art of Verbal Engineering. [Electronic Version]. Duquesne Law Review, 35, 81-108. 
Michalsen, A. \& Reinhart, K. (2006). 'Euthanasia': A Confusing Term, Abused Under the Nazi Regime and Misused in Present End-of-Life Debate. [Electronic Version]. Intensive Care Med, 32, 1304-1310.

Miller, M.M. (1997). Frame Mapping and Analysis of News Coverage of Contentious Issues. [Electronic Version]. Social Science Computer Review, 15, 367-378.

Mitchell, J.B. (2007). Understanding Assisted Suicide: Nine Issues to Consider. Ann Arbor: The University of Michigan Press.

Pollock, J.C. \& Yulis, S.G. (2004). Nationwide Newspaper Coverage of Physician-Assisted Suicide: A Community Structure Approach. [Electronic Version]. Journal of Health Communication, 9, 281-307.

Rietjens, J., Raijmakers, N., Kouwenhoven, P., Seale, C., van Thiel, G., Trappenburg, M., van Delden, J., \& van der Heide, A. (2013). News Media Coverage of Euthanasia: A Content Analysis of Dutch National Newspapers. [Electronic Version]. Bio Medical Ethics, 14.

Rystrom, K. (1983). The Why, Who and How of the Editorial Page. New York: Random House.

Santana, A.D. (2011). Online Readers Comments Represent New Opinion Pipeline. [Electronic Version]. Newspaper Research Journal, 32, 66-81.

Scott, M., \& Tribble, C. (2006). Textual Patterns: Key Words and Corpus Analysis in Language Education. Philadelphia: John Benjamins Publishing Company.

Stonecipher, H.W. (1979). Editorial and Persuasive Writing: Opinion Functions of the News Media. New York: Hastings House, Publishers.

Strate, J.M., Zalman, M., \& Hunter, D.J. (2005). Physician Assisted Suicide and the Politics of Problem Definition. [Electronic Version]. Mortality, 10, 23-41.

Tucker, K.L., \& Steele, F.B. (2007). Patient Choice at the End of Life: Getting the Language Right. [Electronic Version]. Journal of Legal Medicine, 28, 305-325.

Van Dijk, T.A. (1991). Racism and the Press: Critical Studies in Racism and Migration. New York: Routledge.

Van Gorp, B. (2010). Strategies to Take Subjectivity Out of Framing Analysis. In P. D'Angelo \& J.A. Kuyper (Eds.), Doing News Framing Analysis: Empirical and Theoretical Perspectives (pp. 84-109). New York: Routledge.

Van Gorp, B., \& Vercruysse, T. (2012). Frames and Counter-frames giving meaning to Dementia: A Framing Analysis of Media Content. [Electronic Version]. Social Sciences and Medicine, 74, 1274-1281. 
Walker, R.M., \& Black, J. (2009). Terri Schiavo and Televised News: Fact or Fiction? In K.W. Goodmans (Ed.). The Case of Terri Schiavo: Ethics, Politics, and Death in the $21^{\text {st }}$ Century (pp. 210-224). Oxford: Oxford University Press.

Walter, T., Littlewood, J., \& Pickering, M. (1995). Death in the News: The Public Invigilation of Private Emotion. [Electronic Version]. Sociology, 29, 579,596.

Weber, R.P. (1985). Basic Content Analysis. Beverly Hills: Sage Publications.

Williamson, J.M.L., Skinner, C.I., \& Hocken, D.B. (2011). Death and Illness as Depicted in the Media. [Electronic Version]. The International Journal of Clinic Practice, 65, 547-551.

Wissner-Gross, E. (1999). Unbiased: Editing in a Diverse Society. Ames: Iowa State University Press.

Woodthorpe, K. (2010). Public Dying: Death in the Media and Jade Goody. [Electronic Version]. Sociology Compass, 4, 283-294. 